\title{
EL DESARROLLO ECONÓMICO EN MÉXICO
}

Gonzalo Hernández Licona*

RESUMEN: El objetivo de este ensayo es analizar con cifras recientes el desarrollo económico de México. Para poder evaluarlo, se harán mediciones de distintas variables que reflejan este complejo concepto. En primer lugar, se estudia la evolución del nivel de vida promedio de la población, enfatizando la generación de ingreso de sus habitantes. Posteriormente se da cuenta del crecimiento económico del país como la variable que mejor explica el nivel de vida de la población, pues implica mejorar el bienestar de la misma en su totalidad; por ello, el tercer tema será la situación de la distribución del ingreso, para analizar posibles disparidades de bienestar al interior del país. Finalmente, se evalúa la situación de la pobreza en México, como una de las variables que resume el desarrollo económico y que es simplemente el resultado de la evolución de las variables anteriores.

$$
\text { শ্ৰ }
$$

ABSTRACT: The objective of this article is to analyze Mexico's economic development based on recent data. In order to accomplish this goal, we will measure diverse factors reflecting such complex phenomenon. First, we will study the evolution of the standard of life focusing on the income generation capabilities of its population. Then it will be argued that the best explanatory variable for the country's standard of life is the economic growth since it improves the well-being of all population. Consequently the third topic addressed will be the current state of income distribution, allowing us to analyze the country's disparities regarding well-being. Finally, we will analyze the current state of poverty in Mexico as one of the factors summarizing economic growth and as the result of the development of the previous factors.

* Secretario ejecutivo del Consejo Nacional de Evaluación de la Política de Desarrollo Social (CONEVAL). 
PALABRAS CLAVE: México, desarrollo, nivel de vida, crecimiento económico, distribución del ingreso, pobreza, desigualdad.

KEY WORDS: Mexico, development, quality of life, economic growth, income distribution, poverty, inequality.

RECEPCIÓN: 22 de enero de 2013.

APROBACIÓN: 07 de mayo de 2013. 


\section{EL DESARROLLO ECONÓMICO EN MÉXICO*}

\section{Introducción}

\section{$\mathrm{S}_{\text {i hiciéramos un rápido recuento }}$} de lo mejor que tiene México, no habría (casi) disputa en señalar al menos lo siguiente: la riqueza de sus recursos naturales, la diversidad de su geografía, la bondad de su clima, la cultura y su historia e incluso la afabilidad de su gente y su variada comida. Para muchos, la mezcla de todo esto indica que México cuenta con una cultura sobresaliente con respecto a muchos otros países. El cariño y el orgullo por el país, así como una dosis ligeramente elevada de nacionalismo nos ayudan a afianzar esta visión.

Sus 2 millones de kilómetros cuadrados hacen de México uno de los 15 países más grandes del mundo. Sus recursos minerales son ricos y diversos y las reservas de petróleo y gas natural son abundantes. México destaca por la extensión de sus litorales $-11,122 \mathrm{~km}$. exclusivamente en su parte continental-y ocupa el cuarto lugar en existencia de plantas con 25,000 especies registradas.

Para muchos un orgullo del país es su pasado. La historia del país, que puede ser contada en libros o leída en los vestigios de piedra que sobreviven, nos habla de un conjunto de culturas que ya en el siglo XVI tenían un avance social y económico mayor al de gran parte de los países fuera de Europa.

*Agradezco el importante apoyo de Enrique Minor, Florencia Leyson y Luis Gerardo Mejía. 
La mezcla de razas e ideas transformó el país y logró consolidar, quizá, una civilización con mejores elementos que con los que contaba inicialmente. Esta nueva cultura tuvo la capacidad de construir instituciones que hicieron posible, con altas y bajas, con claros y obscuros, forjar un país que empezó a serlo en serio hasta finales del siglo XIX $\mathrm{y}$ que, en la tercera década del siglo Xx, al inaugurarse los períodos de relativo orden y paz social, se podía considerar una sociedad consolidada.

Los avances en materia social y económica que siguieron al desorden revolucionario del siglo XX, así como un creciente nacionalismo que inundó el espíritu de los ciudadanos contagiados por las corrientes internacionales (y que fue alimentado por los distintos gobiernos que buscaban seguir unificando al país), fueron dejando en el imaginario social un indudable y posiblemente necesario orgullo por México.

Qué bueno que así sea, pero también es importante dejar a un lado por un segundo ese orgullo nacional y analizar con frialdad cómo está el país en estos años. La realidad del día a día del México del siglo XXI es un poco distinta a esta idealización. Las riquezas naturales, la historia y los avances del siglo pasado no han sido suficientes para tener hoy día niveles de vida semejantes a los de países con menos recursos naturales, historia, o incluso variedad gastronómica. De acuerdo con cifras oficiales en 2010, el 46.2\% de las personas vivían en pobreza, ${ }^{1}$ el 10\% de las familias más ricas recibía un ingreso promedio 25.2 veces mayor que el de las familias más pobres ${ }^{2}$ y el nivel de vida promedio, medido con el Producto Interno Bruto (PIB) per capita era similar al de países como Croacia, Turquía, Costa Rica, Bosnia y Herzegovina, y Siria. ${ }^{3}$ México podría dar mucho más que esto.

El objetivo de este ensayo es analizar con cifras recientes el desarrollo económico del país. No existe definición única de desarrollo económico, ni siquiera en los libros que tratan este tema de manera formal. ${ }^{4}$

${ }^{1}$ Cifras del Consejo Nacional de Evaluación de la Política de Desarrollo Social (CONEVAL), 2010.

${ }^{2}$ Ibid.

${ }^{3}$ The Conference Board Total Economy Database, January 2012.

${ }^{4}$ Cfr. Debray Ray, Development Economics, 1998, Princeton, Princeton University Press; Dilip Mookherjee y Debray Ray, Readings in the Theory of Economic Development, 2000, 
Por esta razón, para poder evaluar el desarrollo económico de México, haremos mediciones de distintas variables que reflejan este complejo concepto. En primer lugar, analizaremos la evolución del nivel de vida promedio de la población, enfatizando la generación de ingreso de sus habitantes. Posteriormente, daremos cuenta del crecimiento económico del país, como la variable que mejor explica el nivel de vida de la población. El desarrollo económico implica mejorar el bienestar de la población en su totalidad; por ello, el tercer tema será la situación de la distribución del ingreso para analizar posibles disparidades de bienestar al interior del país. Finalmente, evaluaremos la situación de la pobreza en México, como una de las variables que resume todo y que es, simplemente, el resultado de la evolución de las variables anteriores.

\section{Midiendo el desarrollo económico}

\section{Nivel de Vida}

Quizá la variable más importante sea la generación de ingreso de los habitantes. Si bien el desarrollo económico e incluso el nivel de vida deberían ser conceptos mucho más amplios que el ingreso, conocer este último nos puede dar una idea rápida y más o menos efectiva del nivel de bienestar de los países. Para este ensayo tomamos al PIB per capita como la variable que mejor nos puede acercar al nivel de vida ${ }^{5}$ promedio de un país, especialmente desde el punto de vista económico. El PIB per capita es una buena aproximación de los recursos económicos que generan y que obtienen los habitantes de un país en promedio.

Mientras que en términos de PIB total, México ocupa el lugar número 11 a nivel mundial, después de Francia e Italia, ${ }^{6}$ cuando se mide el PIB per capita, México ocupa el lugar 62 de 124 países $^{7}$ (ver Cuadro 1).

Malden, Blackwell Publishers; y Subrata Ghatak, An Introduction to Development Economics, 1986, London, Routledge.

${ }^{5}$ Como se verá más adelante, el Índice de Desarrollo Humano busca ser una medida de las capacidades de los países que refleje mejor la idea de Sen de medir el nivel de vida.

${ }^{6}$ World Economic Outlook Database, April 2012, Fondo Monetario Internacional (FMI).

${ }^{7}$ La comparación se hace utilizando la técnica de la Paridad de Poder de Compra. Ver Angus Maddison, The World Economy: A Millennial Perspective, 2003, Paris, OCDE. 
Luxemburgo, que es el país con mayor PIB per capita, tiene un nivel de vida $389 \%$ mayor que México y la diferencia que tenemos con Estados Unidos es de $296 \%$.

\section{CUADRO 1}

PIB per capita de varios países, 2010 (1990 PPA US\$)

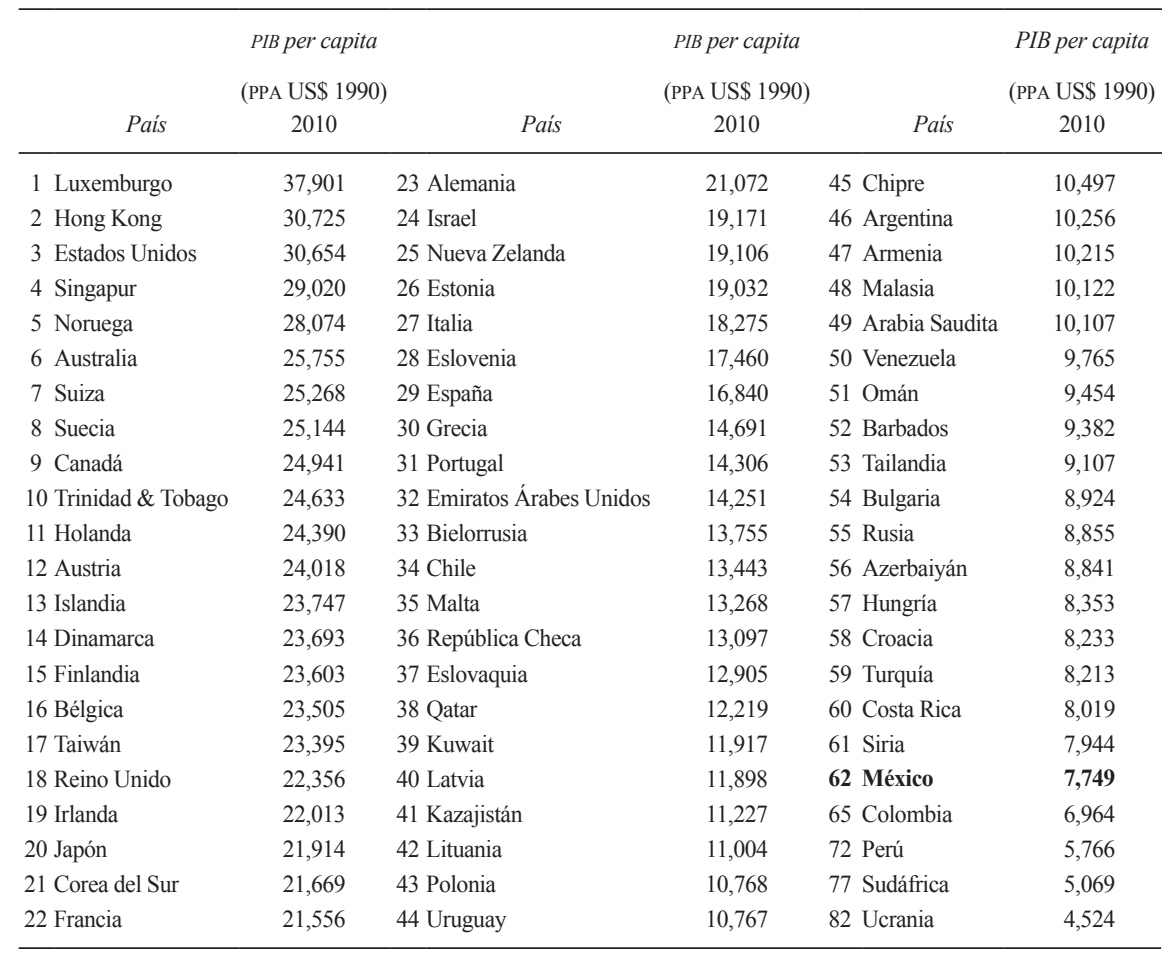

Fuente: The Conference Board Total Economy Database, enero 2012.

Para una evaluación general del nivel de vida en México, pareciera mejor hacer una comparación con países más similares, que no están (o estaban) tan desarrollados. Hoy en día, la familia mexicana promedio tiene un ingreso total de aproximadamente 11,535 pesos al mes. ${ }^{8}$ En Singapur y Hong Kong, una familia promedio percibe casi cuatro veces

${ }^{8}$ Cálculos propios con base en la ENIGH, 2010. El dato incluye ingresos corrientes monetarios y no monetarios. 
más ingreso que una familia mexicana y en Corea del Sur la diferencia es casi el triple. Lo trágico no es que haya países con mejor nivel de vida que México, sino que en 1950, es decir, no hace mucho, todos estos países tenían un ingreso promedio inferior al de nuestro país (Corea era tres veces más pobre que México en términos per capita). Hoy México es el peor de todos ellos, como se puede ver en la Gráfica 1.

\section{GRÁFICA1}

PIB per capita de varios países, 1950-2011 (1990 PPA US\$)

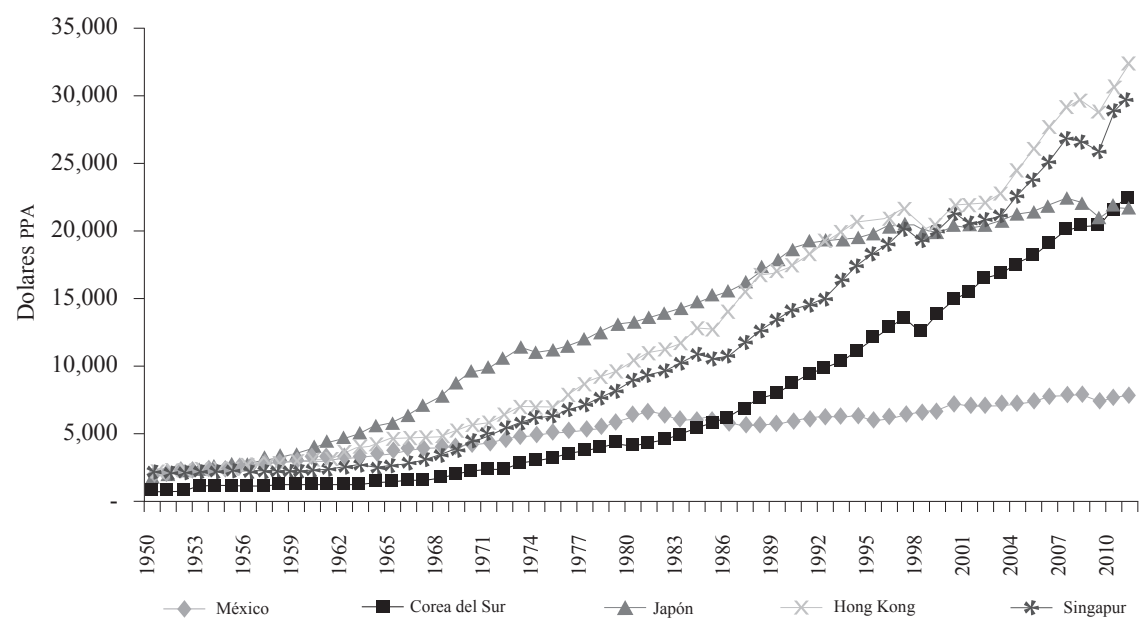

Fuente: Elaboración propia con base en The Conference Board Total Economy Database, enero 2012.

Entre 1950 y 1981 se hablaba del milagro mexicano, pues el nivel de vida promedio creció de manera importante (lo cual sin duda alimentaba el nacionalismo popular). Aun así, Hong Kong y Singapur crecían a un nivel mayor. A partir de 1980, la evolución del nivel de vida es bastante mala: ha quedado prácticamente inalterado en más de 20 años y México, por tanto, está sin duda rezagado respecto de muchos países. 


\section{Índice de Desarrollo Humano}

Una variable que busca incorporar de manera global diversos aspectos del desarrollo es el Índice de Desarrollo Humano (IDH). Este índice fue diseñado hace algunos años por la oficina del Programa de las Naciones Unidas para el Desarrollo (PNUD), siguiendo las recomendaciones y sugerencias de A. Sen, con el objetivo de crear un indicador que diera cuenta de las capacidades (capabilities) promedio de los países. El IDH incluye, además del PIB per capita, los niveles promedios de educación básica y la esperanza de vida promedio de los países, con lo cual se busca conocer qué tantas oportunidades tienen éstos en tres dimensiones del desarrollo: la económica, la educativa y la de salud. ${ }^{9}$ México ocupa el lugar 57 respecto de 187 países, lo cual no nos coloca en una posición mucho mejor que la que teníamos usando el PIB per capita (Gráfica 2).

\section{GRÁFICA2}

Índice de Desarrollo Humano, 2011

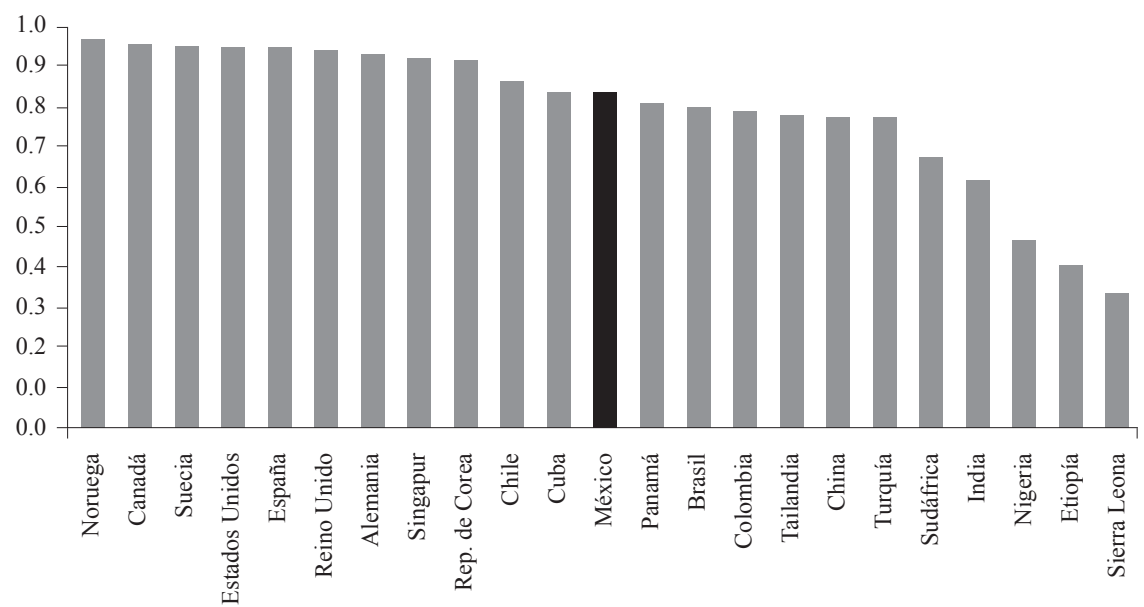

Fuente: Human Development Report 2011, PNUD.

${ }^{9}$ PNUD, Human Development Report 2003, New York, Oxford University Press. 
Esto quiere decir que, si bien México ha tenido logros significativos en cuanto al acceso a servicios y está en una posición más cercana a países desarrollados en esperanza de vida y acceso a educación básica, la variable que retrasa al país sigue siendo la generación de ingreso. Esta variable es la que refleja, día a día, los recursos que se llevan a casa las familias. Si bien el país tiene un nivel de vida mayor que muchos países del mundo, sus rezagos lo colocan a media tabla en el concierto internacional, en una posición francamente mediocre.

\section{Crecimiento económico}

¿De qué depende el nivel de vida de un país? Primordialmente, del crecimiento económico promedio que haya tenido en las décadas anteriores. La diferencia en el nivel de ingreso entre México y otros países es producto de las diferencias en el nivel de crecimiento económico durante un período largo de tiempo. ${ }^{10}$ Para explicar el hecho de que el nivel de vida de México hoy en día haya quedado tan rezagado respecto de estos países, no hay que fijarse en lo que pasa en un año en particular, sino en el crecimiento económico de largo plazo: mientras que en 62 años el crecimiento promedio del PIB per capita en México fue de $2.0 \%$, éste fue de $5.5 \%, 4.4 \%$ y $4.5 \%$ en Corea del Sur, Singapur y Hong Kong, respectivamente. Lo anterior se puede ver en la Gráfica 1: el hecho de que, entre 1982 y 2011, el nivel de vida no haya cambiado se debe a que la pendiente de la evolución del PIB per capita para México, es decir, el crecimiento económico, fue prácticamente nulo.

Para tener muchos más ingresos de los que tenemos hoy no necesitábamos crecer a la impresionante tasa de los países asiáticos. Con sólo haber aumentado nuestro crecimiento promedio desde 1950 en un insignificante punto porcentual - de $2.0 \%$ a $3.0 \%$ por ejemplo- tendríamos hoy un ingreso familiar promedio $60 \%$ más alto del que hoy tenemos. Con un punto adicional de crecimiento promedio de manera sostenida, las familias mexicanas seríamos hoy $60 \%$ más ricas. Evidentemente, en

\footnotetext{
${ }^{10}$ Robert J. Barro y Xavier Sala-i-Martin, Economic Growth, 20032 , Boston, The MIT Press.
} 
México no hicimos lo que debimos hacer; por ello, nuestro nivel de vida es bastante pobre. El nivel de vida que hoy tenemos depende de lo que hicimos o dejamos de hacer para acelerar el crecimiento económico en las últimas décadas.

Entre 1950 y 1981, el crecimiento promedio (per capita) fue de $3.4 \%$; posteriormente ha sido de sólo $0.6 \%$. Si bien se observó un crecimiento importante en los períodos 1988-2000, los períodos de reducción del crecimiento trajeron consigo un crecimiento neto muy bajo entre 1981 y 2011, que se tradujo en un casi nulo avance en el nivel de vida promedio. El bajo crecimiento se refleja también en el mercado laboral. En promedio, cada año se incorporan entre 1.1 y 1.2 millones de personas al mercado laboral. Se estima que de 1996 a 2010 el promedio de empleos formales generados por año fue de sólo 361 mil. ${ }^{11}$

¿Por qué ha habido tan bajo crecimiento en México, especialmente a partir de 1981? De acuerdo a J. Santaella, el menor crecimiento económico se debió al "abandono de una política macroeconómica prudente a partir de 1972 [...] La evolución del gasto gubernamental y la tasa de inflación son consistentes con la hipótesis de que la inestabilidad macroeconómica producida por políticas expansivas pudiera estar detrás de la caída secular del crecimiento económico". ${ }^{12}$ El autor afirma también que el marco institucional del país dejó de ser conducente para el desarrollo económico.

Quizás una de las variables que mejor puede explicar el crecimiento económico de un país es el crecimiento de la productividad. Este es el grado en que el país, con los mismos recursos, puede aumentar el valor agregado año con año. De acuerdo a J. Santaella, el crecimiento de la productividad de todos los factores en conjunto -el crecimiento de la productividad factorial total- ha venido decreciendo en México desde los años cincuentas e incluso fue negativo desde inicios de los ochentas.

${ }^{11}$ Se refiere a trabajadores permanentes y eventuales asegurados en el Instituto Mexicano del Seguro Social durante ese período (INEGI, 2012).

${ }^{12} \mathrm{~J}$. Santaella, "El crecimiento económico de México: explorando las causas de su caída secular", Gaceta de Economía, año 3, núm. 6, 1988, p. 43. 
El crecimiento de la productividad es el motor que alienta el crecimiento económico. Fomentar el crecimiento de la productividad mediante mayor capital físico, mayor capital humano (mejorando tanto la cobertura como la calidad de la educación formal y la capacitación), mejoras tecnológicas, más infraestructura, menores precios de los insumos para la producción, un mercado de capitales más amplio y arreglos institucionales satisfactorios son la vía para mejorar el crecimiento del país. No está de más subrayar que un crecimiento sostenido de la productividad se traducirá en un mayor nivel de vida (medido en PIB per capita) en el mediano plazo.

Un balance de la evolución de algunas de las variables que pueden fomentar la productividad muestra que hay un largo trecho que recorrer en nuestro país. Nos estamos rezagando en relación a otros y, en un mundo globalizado (en el que ahora estamos inmersos, para bien o para mal) el menor avance de la productividad y la competitividad respecto del resto de los competidores significa, en la práctica, un avance nulo en términos de nivel de vida y creación de empleos formales.

En educación, a pesar de los avances registrados en cobertura en todos los niveles, especialmente primaria, hay aún rezagos importantes respecto de otros países. Mientras que en Corea del Sur la escolaridad promedio es de 11.6 años, en México es de 8.5..$^{13}$ En el año 2010, las tasas de asistencia escolar para niños entre 6 y 11 años, niños entre 12 y 14 años, niños entre 15 y 17 años y personas entre 18 y 25 años fueron de $98.3 \%, 91.6 \%, 66.3 \%$ y $27.6 \%$ respectivamente, ${ }^{14}$ y en términos de calidad educativa seguimos en los últimos lugares, al compararnos con el resto de los países más avanzados.

La situación de la infraestructura en México se encuentra atrasada también. El Cuadro 2 muestra los rezagos de México frente a Singapur en términos de infraestructura. En líneas telefónicas, carreteras pavimentadas y tuberías de gas, la distancia con el país asiático es clara.

${ }^{13}$ PNUD, Human Development Report 2011, New York, Oxford University Press.

${ }^{14}$ Consejo Nacional de Evaluación de la Política de Desarrollo Social, Informe de Evaluación de la Política de Desarrollo Social en México, 2011, México, p. 28. 
GRÁFICA 3

Educación promedio, 1985-2010

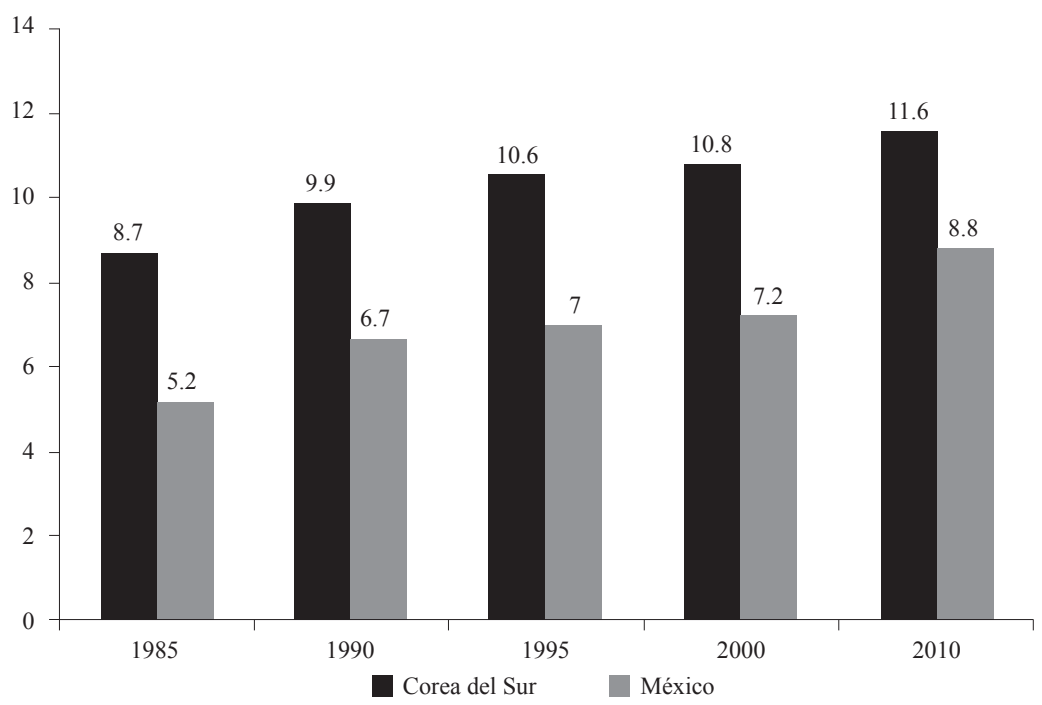

Fuente: Human Development Report 2011, PNUD.

CUADRO 2

\section{Comparación México-Singapur}

\begin{tabular}{lcc}
\hline \multicolumn{1}{c}{ Indicador } & Singapur & México \\
\hline Infraestructura (líneas telefónicas por $100 \mathrm{hab}$. ) & 42.6 & 17.9 \\
Infraestructura (líneas telefónicas móviles por $100 \mathrm{hab})$. & 156.9 & 82.2 \\
Carreteras pavimentadas (longitud por cada $100 \mathrm{~km}^{2}$ ) & 481.5 & 6.8 \\
Tuberías de gas (longitud por cada $100 \mathrm{~km}^{2}$ ) & 16.2 & 0.9 \\
\hline
\end{tabular}

Fuentes: World Factbook, CIA, 2012.

Las instituciones, es decir, la forma de hacer las cosas -las reglas del juego, formales o informales- afectan también la productividad y el crecimiento. El exceso de regulaciones afecta el crecimiento económico, pues no se brinda certidumbre a la inversión.

En términos de regulación empresarial, para poner un solo ejemplo, las comparaciones no son favorables para nuestro país en el ámbito internacional. El Instituto Fraser calificó en 2009 el grado de libertad 
económica y México obtuvo un 6.74 (en una escala del 0 al 10). Singapur obtuvo una calificación de 8.68. ${ }^{15}$ Asimismo, de acuerdo con el Banco Mundial, México se encuentra en el lugar 53 de 183 países en lo que respecta a la facilidad para abrir un negocio, lejos de países como $\mathrm{Ca}$ nadá, Estados Unidos y Singapur, que ocupan los lugares 1, 4 y 13, respectivamente. ${ }^{16}$ Las mayores trabas para la creación de empresas formales se traducirán, necesariamente, en un menor crecimiento y generación de empleos formales.

Finalmente, otro factor que sin duda afecta la productividad y las expectativas de inversión es la falta de un verdadero Estado de derecho. El Cuadro 3 indica que México tiene calificaciones muy pobres, tanto en el respeto a los derechos de propiedad, y a la imparcialidad de los juzgados, como en términos de corrupción.

CUADRO 3

Respeto a la Ley en varios países, 2010

\begin{tabular}{lcccc}
\hline & $\begin{array}{c}\text { Derechos } \\
\text { de propiedad }\end{array}$ & $\begin{array}{c}\text { Imparcialidad } \\
\text { judicial }\end{array}$ & $\begin{array}{c}\text { Imparcialidad } \\
\text { de los juzgados }\end{array}$ & $\begin{array}{c}\text { Índice } \\
\text { de corrupción }\end{array}$ \\
\hline Finlandia & 6.4 & 6.3 & 7.0 & 9.2 \\
Singapur & 6.3 & 5.6 & 8.2 & 9.3 \\
Canadá & 6.1 & 6.2 & 6.7 & 8.9 \\
Chile & 5.2 & 5.4 & 6.1 & 7.2 \\
EUA & 5.1 & 5 & 5.8 & 7.1 \\
España & 4.9 & 3.8 & 4.4 & 6.1 \\
México & $\mathbf{3 . 9}$ & $\mathbf{3 . 2}$ & $\mathbf{3 . 7}$ & $\mathbf{3 . 1}$ \\
Guatemala & 3.7 & 2.7 & 3.5 & 3.2 \\
Bolivia & 2.2 & 2.29 & 2.0 & 2.8 \\
Venezuela & 1.8 & 1.7 & 1.3 & 2 \\
\hline
\end{tabular}

Fuente: Governance Indicators Database (DataGob), BID.

La gran impunidad que prevalece en México, percibida en distintos ámbitos, nos habla de un Estado de derecho muy poco sólido y que, además de inhibir la inversión productiva, invita a la realización de acti-

${ }^{15}$ Fraser Institute, Economic Freedom of the World 2011. Annual Report, Vancouver, p. 7.

${ }^{16}$ The World Bank, Doing Business 2012: Doing Business in a More Transparent World, 2012. 
vidades u ocupaciones que puedan estar al margen de la ley y que no contribuyen, en el largo plazo, al mayor crecimiento del país. No pagar impuestos, robarse la electricidad, utilizar la vía pública para vender artículos, vender mercancía robada, o pirata, corromper autoridades o dedicarse de lleno a actividades francamente delictivas (robos, secuestros, extorsión) puede ser atractivo si los costos son bajos. Lo anterior fomenta la inversión de escala pequeña e ilegal e inhibe la inversión productiva y el crecimiento de largo plazo. El nombre del juego es impunidad.

Después de este balance que afecta la productividad y la competitividad de México, no es de extrañar que la inversión, una de las fuentes más importantes de crecimiento, no haya tenido en México un avance suficiente. En un mundo globalizado el reto es hacer las cosas mejor y más rápido que otros, para que las fuentes de financiamiento de la inversión en capital físico, en capital humano y en tecnología, los motores del crecimiento económico, crezcan en nuestro país.

\section{Distribución del ingreso}

Los promedios son muy útiles para conocer de manera sucinta la realidad de una variable. En el caso del nivel de vida, como ya vimos, podemos decir que México tiene un mejor nivel de vida que Ucrania, pues el PIB per capita del primero en 2010 fue de 7,749 dólares y del segundo de 4,524 dólares. ${ }^{17}$ Es decir, en promedio, los habitantes de México tienen un mejor poder adquisitivo que los habitantes de Ucrania. ${ }^{18}$

Pero un aspecto fundamental del desarrollo es saber si existen discrepancias grandes en el nivel de vida de sus habitantes. Pensemos en dos países conformados por 2 individuos cada uno. En el país A los dos individuos ganan $\$ 100$ y por tanto el ingreso promedio (el nivel de vida promedio) es $\$ 100$. En el país B una persona gana $\$ 0$ y la otra

${ }^{17}$ Dólares americanos de 1990, ajustados por poder de paridad de compra.

${ }^{18}$ Ver Cuadro 1. 
gana \$200; en este país, el nivel de vida promedio también es \$100. El pastel total en los dos países es del mismo tamaño y en términos de eficiencia económica ambos casos serían parecidos, ${ }^{19}$ pero la desigualdad sería muy distinta y, por ello, el desarrollo económico debería ser distinto entre ambos países.

¿Por qué el aspecto distributivo tiene importancia en el desarrollo? Mencionemos brevemente algunas razones. En primer lugar, desde el punto de vista de la justicia distributiva, diversas corrientes filosóficas, entre ellas la corriente utilitarista -bajo ciertos supuestos-, así como los modelos de justicia desarrollados por J. Rawls y H. Varian, apuntan a que, con un tamaño fijo del pastel, la desigualdad en la repartición del mismo se traduciría en un menor nivel de bienestar generalizado.

Asimismo, la desigualdad en la asignación y generación de recursos inhibe la competencia económica de las sociedades, dejando a grupos importantes de la población sin la posibilidad de competir realmente en el ámbito económico, tanto en el consumo como en la producción. Finalmente, el crecimiento económico reduce en mayor medida la pobreza mientras menor sea la desigualdad inicial del país. ${ }^{20}$

\section{Desigualdad en México}

México se destaca, desafortunadamente, por ser uno de los países más desiguales del mundo. El índice de Gini es una medida de desigualdad comúnmente utilizada en comparaciones internacionales, que puede tomar valores entre 0 (mínima desigualdad) y 1 (máxima desigualdad). En el Cuadro 4, se observa que México tiene una peor distribución del ingreso que países como Suecia o Estados Unidos, pero también tiene mayor desigualdad que Ucrania, Etiopía, Vietnam, Nigeria, Kenia o Burkina Faso. En general, los países latinoamericanos y africanos tienen las peores distribuciones del ingreso en el mundo y México destaca entre ellos.

${ }^{19}$ Es decir, en ambos países no podríamos mejorar a una persona sin perjudicar a la otra.

${ }^{20}$ N. Kakwani, "Growth Rates of Per Capita Income and Aggregate Welfare: an International Comparison", The Review of Economics and Statistics, vol. 79, núm. 1, mayo 2000, pp. 201-11. 


\section{CUAdRo 4}

\section{Coeficiente de GINI para diferentes países}

\begin{tabular}{lcc}
\hline \multicolumn{1}{c}{ País } & Coeficiente de GINI por ingreso en el hogar \\
\hline Sudáfrica & 0.63 & $(2009)$ \\
Colombia & 0.56 & $(2010)$ \\
Brasil & 0.55 & $(2009)$ \\
Chile & 0.52 & $(2009)$ \\
Nigeria & 0.49 & $(2010)$ \\
México & $\mathbf{0 . 5 2}$ & $\mathbf{2 0 0 8 )}$ \\
Uruguay & 0.45 & $(2010)$ \\
Argentina & 0.46 & $(2009)$ \\
EUA & 0.45 & $(2007)$ \\
Tailandia & 0.40 & $(2009)$ \\
Nepal & 0.33 & $(2010)$ \\
Bangladesh & 0.32 & $(2010)$ \\
Ucrania & 0.27 & $(2008)$ \\
Suecia & 0.23 & $(2005)$ \\
\hline
\end{tabular}

Fuentes: World Development Indicators 2012, World Bank. Para México, EUA y Suecia la fuente es The World Factbook, CIA 2012.

CUADRO 5

Distribución del ingreso corriente total de los hogares por deciles, 1992-2010

\begin{tabular}{crrrrrrrrrr}
\hline $\begin{array}{c}\text { Deciles de } \\
\text { hogares }\end{array}$ & 1992 & 1994 & 1996 & 1998 & 2000 & 2002 & 2004 & 2006 & 2008 & 2010 \\
\hline I & 1.6 & 1.5 & 1.8 & 1.5 & 1.5 & 1.7 & 1.6 & 1.8 & 1.7 & 1.8 \\
II & 2.8 & 2.7 & 3.0 & 2.7 & 2.7 & 2.9 & 2.9 & 3.1 & 2.9 & 3.1 \\
III & 3.8 & 3.7 & 3.9 & 3.7 & 3.7 & 3.9 & 4.0 & 4.1 & 3.9 & 4.1 \\
IV & 4.8 & 4.6 & 4.9 & 4.7 & 4.6 & 4.9 & 5.0 & 5.1 & 4.9 & 5.2 \\
V & 5.8 & 5.7 & 6.0 & 5.8 & 5.7 & 6.1 & 6.0 & 6.2 & 6.0 & 6.4 \\
VI & 7.2 & 7.1 & 7.3 & 7.3 & 7.1 & 7.4 & 7.4 & 7.4 & 7.4 & 7.7 \\
VII & 8.9 & 8.8 & 8.9 & 8.9 & 8.8 & 9.2 & 9.1 & 9.2 & 9.2 & 9.5 \\
VIII & 11.3 & 11.4 & 11.5 & 11.6 & 11.3 & 11.9 & 11.7 & 11.6 & 11.7 & 12.0 \\
IX & 15.8 & 16.2 & 15.9 & 15.9 & 16.0 & 16.5 & 16.2 & 15.8 & 16.1 & 16.3 \\
X & 38.0 & 38.3 & 36.8 & 37.9 & 38.6 & 35.5 & 36.1 & 35.7 & 36.2 & 33.9 \\
Total & $\mathbf{1 0 0 . 0}$ & $\mathbf{1 0 0 . 0}$ & $\mathbf{1 0 0 . 0}$ & $\mathbf{1 0 0 . 0}$ & $\mathbf{1 0 0 . 0}$ & $\mathbf{1 0 0 . 0}$ & $\mathbf{1 0 0 . 0}$ & $\mathbf{1 0 0 . 0}$ & $\mathbf{1 0 0 . 0}$ & $\mathbf{1 0 0 . 0}$ \\
\hline
\end{tabular}

Fuente: Cálculos propios con base en las ENIGH 1992-2010 
Otra forma de analizar este fenómeno es observar la distribución del ingreso al interior del país. Si ordenáramos a las familias de México, de la más pobre a la más rica, y después formáramos diez grupos de igual tamaño, obtendríamos 10 deciles. En el primer decil estaría el 10\% más pobre del país y en el décimo decil se encontraría el 10\% de las familias más ricas del país. El Cuadro 5 muestra cómo ha estado distribuido el ingreso en México de 1992 hasta 2010. Se observa que para 2010, el 10\% de los hogares más pobres recibía (o generaba) sólo el $1.8 \%$ del ingreso total generado en el país. A su vez, el 10\% de las familias más ricas -el décimo decil-generaba el 33.9\% del ingreso total de México. Si bien, comparando la distribución del ingreso entre 1992 y 2010, se observa una ligera mejoría en la desigualdad, la estructura de la distribución de los ingresos sigue mostrando una alta concentración del ingreso en el país.

La comparación con niveles de ingreso pudiera ser más ilustrativa. Mientras que en 2010, en promedio las familias del décimo decil ganaban $\$ 39,107.1$ mensuales (a pesos de agosto 2010), las familias del primer decil, las más pobres, ganaban en promedio $\$ 2,036.5$. Es decir, la diferencia en el promedio de ingresos entre ambos deciles es de aproximadamente 1,820.3\% ${ }^{21}$ En países con grandes desigualdades, como en México, la brecha entre pobres y ricos puede ser abismal.

CUAdRO 6

Estadísticas por deciles de ingreso, 2010

\begin{tabular}{cccc}
\hline Decil & $\begin{array}{c}\text { Años promedio } \\
\text { en educación }\end{array}$ & $\begin{array}{c}\text { Ingreso promedio } \\
\text { familiar }\end{array}$ & $\begin{array}{c}\text { Gasto promedio en } \\
\text { alimentación }\end{array}$ \\
\hline I & 4.8 & $2,036.5$ & $1,218.1$ \\
II & 5.8 & $3,594.3$ & $1,505.0$ \\
III & 6.7 & $4,802.7$ & $1,803.0$ \\
IV & 7.3 & $6,043.3$ & $1,968.7$ \\
V & 7.8 & $7,361.8$ & $2,151.7$ \\
VI & 8.4 & $8,918.5$ & $2,409.1$ \\
VII & 8.9 & $10,933.1$ & $2,751.5$ \\
VIII & 9.6 & $13,828.3$ & $3,020.9$ \\
IX & 10.6 & $18,740.6$ & $3,554.5$ \\
X & 12.6 & $39,107.1$ & $4,901.8$ \\
\hline
\end{tabular}

Fuente: Cálculos propios con base en la ENIGH 2010.

${ }^{21} \mathrm{La}$ brecha entre la familia más rica y la más pobre de México necesariamente es mayor. 
Las diferencias de ingreso entre la población se traducen en satisfacciones de necesidades también distintas, e incluso peligrosas. Como se puede observar en el Cuadro 6, el gasto en alimentación es muy distinto entre niveles de ingreso. Dado que en los deciles más bajos este gasto es muy reducido, podría no ser suficiente para cubrir las mínimas necesidades de alimentación por familia.

\section{¿Cómo explicar la mala distribución del ingreso?}

Esta respuesta no es sencilla; la literatura reporta innumerables explicaciones. Intentaremos dar aquí algunas posibles respuestas que, evidentemente, no son las únicas posibles.

\section{Distribución de activos}

Attanasio y Székely ${ }^{22}$ han mostrado, como otros autores, que el ingreso que obtienen las familias tiene como fuente principal los activos que ellas posean, es decir, el capital, la tierra, y el capital humano transformado en fuerza de trabajo. El ingreso dependerá de tres factores relacionados con los activos: la cantidad, la utilización y el precio. Para el caso de México, los activos están mal distribuidos y ello ayuda a entender la mala distribución del ingreso.

Para ejemplificar esta visión, tomemos el caso de la educación. El Cuadro 6 muestra que el nivel de escolaridad es muy distinto entre deciles. Mientras que el primer decil tiene un nivel de educación promedio de 4.8 años, el decil más rico tiene 12.6 años. La causalidad es en este caso doble, lo cual magnifica la desigualdad: quien tuvo menos educación genera menos ingresos, pero también más ingresos mejoran la oportunidad de tener más años de educación.

Esto último es importante, pues quien tiene más recursos no sólo tiene posibilidad de financiar más años de educación, sino que también

${ }^{22}$ Orazio Attanasio y Miguel Székely, "La pobreza en América Latina: un análisis basado en los activos”, El Trimestre Económico, (263), vol. 66, núm. 3, julio-septiembre, 1999, pp. 317-64. 
buscará la mejor calidad posible. La Gráfica 4 señala que los deciles mayores gastan más en educación, es decir, tienen la posibilidad de buscar mejor calidad en las escuelas.

La cantidad y calidad de la educación, un activo importantísimo para generar ingresos, está mal distribuido. Otros activos -acceso a capital físico, tierra, etc.- tienen el mismo problema. ¿Cómo se comporta la utilización del capital humano?

Para medir la utilización del activo capital humano utilizaremos la tasa de participación laboral, esto es, el porcentaje de personas de 14 años o más que están ocupadas o buscan empleo. Para el caso de los hombres, la tasa de participación es más o menos constante por decil de ingreso y fluctúa entre el $79 \%$ y el $83 \%$, lo cual indica que la participación de los hombres en el mercado laboral es relativamente alta y no hay diferencias grandes entre deciles. ${ }^{23}$ Esto no sucede con las mujeres.

GRÁFICA4

Gasto en educación por decil de ingreso, 2010

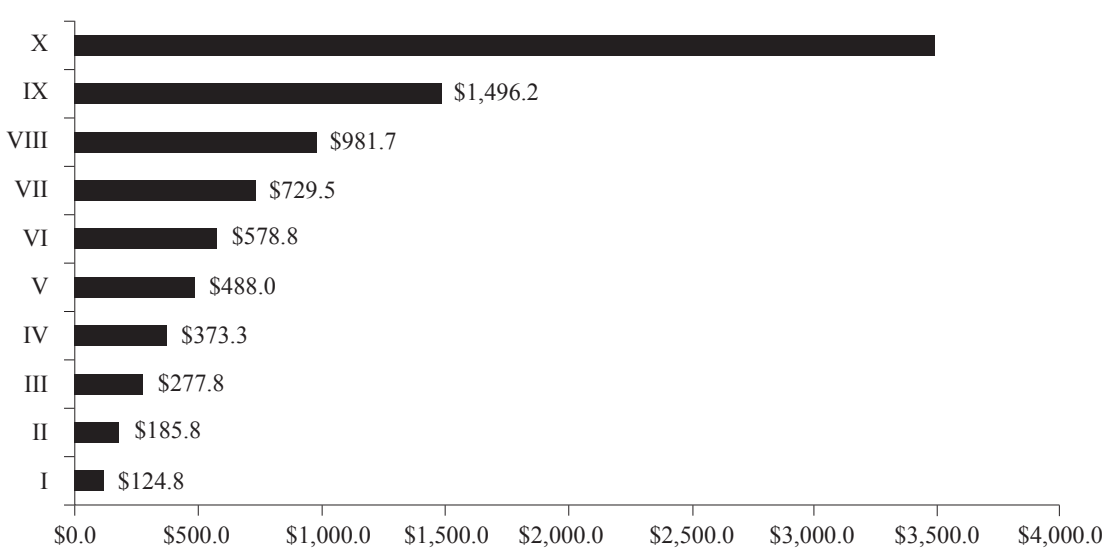

Fuente: Cálculos propios con base en la ENIGH 2010.

Las mujeres más pobres utilizan menos su activo más importante, la fuerza laboral, para obtener ingresos. Mientras que el 53.7\% de las mu-

${ }^{23}$ Cálculos propios con base en la ENIGH, 2010. 
jeres en el decil más alto participan en el mercado laboral, las más pobres lo hacen en un $28.7 \%$. El efecto sobre el ingreso total y sobre la desigualdad, comparando el ingreso con las mujeres con más educación, es importante. En promedio, una mujer de 14 años o más puede ganar \$244.8 en el primer decil (que es la combinación de su probabilidad de trabajar y el salario promedio que tendría si trabajara), mientras que una mujer en el décimo decil podría tener un ingreso esperado de $\$ 6,622.2 .^{24}$

Las barreras de las mujeres más pobres para trabajar son diversas. Además de la discriminación y el comportamiento tradicional de los hogares más pobres, las familias pobres tienen más hijos que las familias ricas, lo cual indica que la participación laboral tiene que ser menor. Asimismo, con menores niveles de ingreso, es menos factible poder pagar guarderías o servicios del hogar que permitan dedicar más tiempo al trabajo.

Finalmente, analicemos el precio al que se intercambia el activo educación, el salario por niveles educativos. En 2010, una persona con nivel educativo de universidad o más recibía en promedio $\$ 9,505$ al mes; quien tenía primaria completa, recibía en promedio \$2,051 (el promedio de una persona sin escolaridad fue $\$ 971$ mensuales). Si bien otras características afectan el salario, se observa lógicamente que a mayor educación se tiene un mayor nivel de ingreso. La razón entre el ingreso de personas con universidad y de primaria fue de 4.6. ${ }^{25}$

\section{Situación geográfica}

La desigualdad a nivel individual (o familiar) del país puede también observarse a nivel regional. La Gráfica 5 indica que a nivel estatal también se tiene una marcada desigualdad. Mientras que en el Distrito Federal el PIB per capita mensual fue de cerca de \$20,210.3 en 2010, en Chiapas y Oaxaca se generaron sólo \$8,419.6 en promedio.

${ }^{24}$ Ibid.

${ }^{25}$ Cálculos propios con base en la ENIGH, 2010. 
Hay muchas explicaciones posibles sobre este fenómeno. En primer lugar, la distribución de población indígena en el país. A excepción de Yucatán y Quintana Roo, que tienen altos porcentajes de población indígena y que no figuran entre los estados con menor nivel de vida, en general hay una correlación negativa entre PIB y porcentaje de población indígena. Si la desigualdad del ingreso proviene de tener menos oportunidades para generar ingreso -menos oportunidad de tener más y mejor educación, menos inserción en mercados grandes, menos posibilidad de tener técnicas de cultivo y producción eficientes, menos acceso a la justicia, más discriminación en el mercado laboral- entonces los indígenas padecen todas estas agravantes.

\section{GRÁFICA5}

PIB per capita mensual por estado, 2010

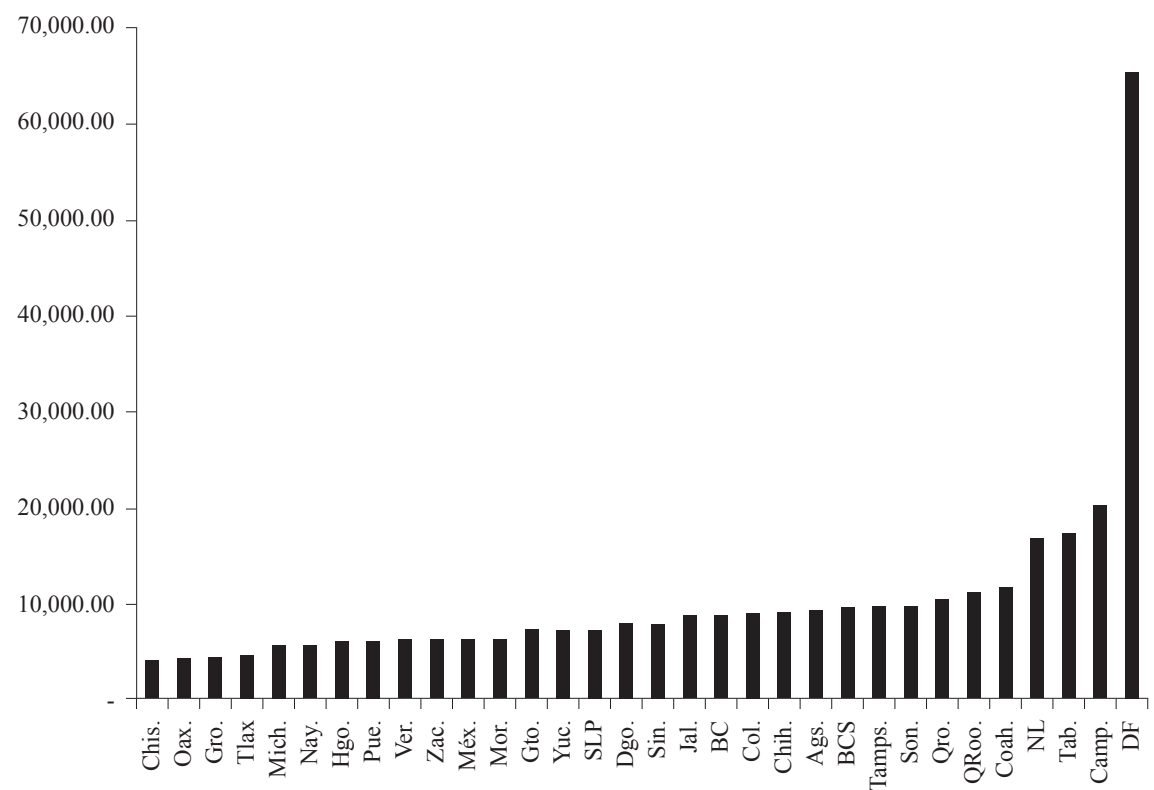

Fuentes: Sistema de Cuentas Nacionales de México y Censo de Población 2010, INEGI.

Una segunda explicación es la infraestructura del país, naturalmente sesgada hacia el centro y norte, especialmente la de comunica- 
ciones y transportes. De acuerdo con E. Dávila, G. Kessel y S. Levy, ${ }^{26}$ estados como Chiapas, Guerrero, Oaxaca, e incluso partes de Hidalgo y Veracruz, no poseen infraestructura suficiente para que puedan asentarse empresas en lugares relativamente remotos y aprovechar los salarios bajos de esas poblaciones. Así como las empresas nacionales e internacionales buscan lugares como China, la India o Taiwán para colocar sus plantas y mejorar sus costos -lo cual implica empleo en la región y eventualmente un incremento de la productividad y los salarios- en México no se aprovecha este elemento, pues introducir materias primas al sureste y enviar los productos terminados a grandes centros de consumo (como el D.F. o Estados Unidos) implicaría altos costos de transporte. Actualmente, se puede ver que las grandes carreteras que soportan cargas pesadas no llegan a puntos estratégicos de altas concentraciones de pobreza, como sucede en varios estados del sur-sureste.

\section{Colonización: la historia también cuenta}

El Banco Mundial ${ }^{27}$ llevó a cabo un estudio sobre la desigualdad en América Latina y le dio un enfoque novedoso (al menos para los economistas) al incluir un capítulo especial sobre la importancia de la forma de colonización sobre la distribución del ingreso actual. En el capítulo sobre las raíces históricas de la desigualdad (y en trabajos anteriores de L. S. Engerman y K. Sokoloff), ${ }^{28}$ se señala que la abundancia de tierras y de recursos naturales favorecieron en América Latina el uso intensivo de mano de obra esclava o nativa. El mayor poderío bélico y social de los españoles y portugueses derivó en la creación de élites cerradas que dominaron y se adueñaron de la producción, dejando al

${ }^{26}$ Enrique Dávila, Georgina Kessel y Santiago Levy, "El sur también existe: un ensayo sobre el desarrollo regional de México", Economía Mexicana, Nueva Época, vol. 11, núm. 2, segundo semestre, 2002, pp. 205-60.

${ }^{27}$ The World Bank, Inequality in Latin America and the Caribbean: Breaking with History?, 2003, Washington, World Bank.

${ }^{28}$ Stanley Engerman y Kenneth L. Sokoloff, "Factor Endowments, Institutions, and Differential Paths of Growth Among New World Economies: A View from Economic Historians of the United States", en Stephen Haber (ed.), How Latin America Fell Behind. Essays on the Economic Histories of Brazil and Mexico, 1800-1914, 1997, Stanford, Stanford University Press, pp. 260-304. 
trabajo esclavo con pocos privilegios y pocas oportunidades. Los autores señalan que la evolución de las instituciones resultó en mayores privilegios para las élites, mismos que han subsistido hasta estos días.

La Gráfica 6 indica que si bien la desigualdad entre los países de un mismo continente puede variar, los países de América Latina y África presentan niveles de desigualdad mayores que en otros continentes. El común denominador es que ambos continentes fueron colonizados por varios siglos. Los efectos de la colonización y las instituciones que se crearon pueden tener repercusiones importantes en la desigualdad que hoy vivimos.

GRÁFICA 6

Coeficiente de Gini para varios países (2000s)

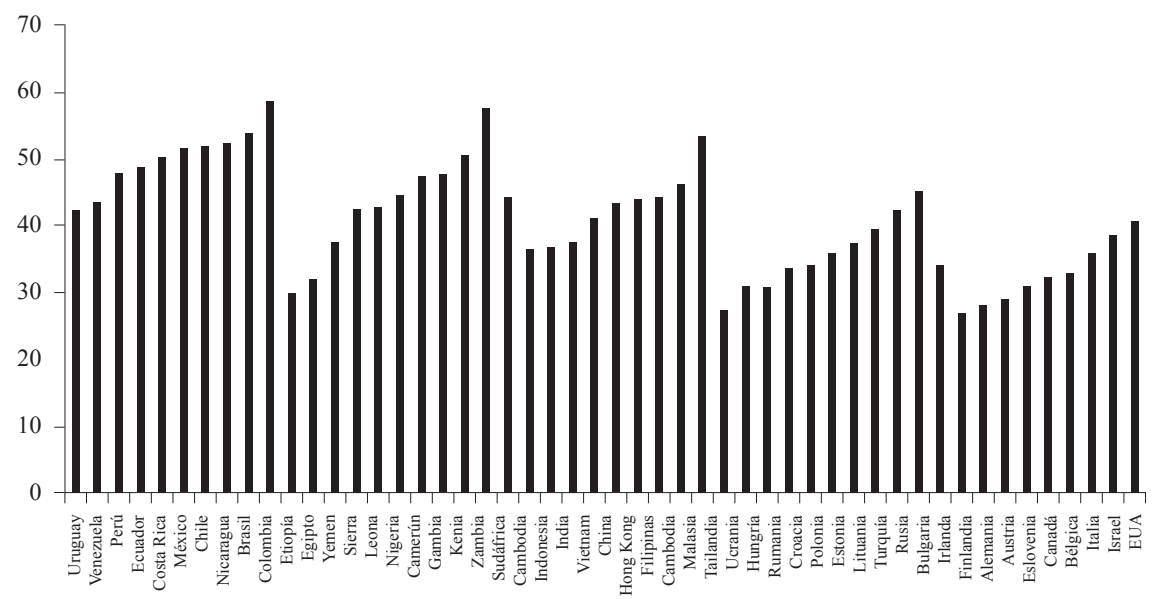

Desigualdad en el décimo decil

El fenómeno de la desigualdad en México, como ya se dijo, implica que un reducido porcentaje de familias gana mucho y que muchas familias generan pocos recursos. Una distribución del ingreso con estas características tiene forma de embudo: son muy pocos los que pueden pasar por la parte más delgada. En México, y en general en América Latina, este fenómeno es especialmente importante. 
En 1998, el Banco Interamericano de Desarrollo estimó los coeficientes de Gini para varios países latinoamericanos y los comparó con la distribución del ingreso de Estados Unidos. Como ya se vio, el Gini de Estados Unidos es muy inferior (Cuadro 4). Sin embargo, se recalcularon estos índices para todos los países, incluyendo Estados Unidos, pero eliminando al decil más alto. Los índices de los países latinoamericanos fueron ahora increíblemente parecidos a los de Estados Unidos. Lo anterior quiere decir que para México la distribución del ingreso al interior del décimo decil es tan mala -o más- como lo es para la distribución completa; por tanto, un elemento que ayuda a entender la mala distribución del país es la concentración de ingresos y oportunidades entre las familias más ricas.

Ejemplifiquemos lo anterior para el caso de México. De acuerdo con la Encuesta Nacional de Ingresos y Gastos de los Hogares (ENIGH) 2010, para pertenecer al 10\% de las familias más ricas bastaba con ganar $\$ 22,862.4$ mensuales en total (a pesos de agosto de 2010), incluyendo el ingreso laboral y no laboral de todos sus miembros. ${ }^{29}$ Esto quiere decir que al interior del décimo decil hay una muy mala distribución del ingreso. Las grandes oportunidades en este país son realmente para muy pocas familias. Un dato más: de acuerdo con la misma fuente, para pertenecer al 5\% de las familias más ricas del país bastaba con ganar $\$ 31,017.7$ mensuales totales.

\section{Desigualdad y crecimiento económico}

Existe un debate serio sobre la relación entre crecimiento y desigualdad, y la causalidad entre ambas variables. Como se mencionó anteriormente, diversos autores afirman que hay una relación inversa entre crecimiento y desigualdad. Por ejemplo, Kuznets ${ }^{30}$ afirmaba que a medida que el país crece, se tiene primero un efecto negativo sobre la desigualdad, pero posteriormente ésta mejora, con lo que se obtiene la famosa U invertida de Kuznets.

${ }^{29} \mathrm{El}$ cálculo anterior no controla por tamaño de la familia.

${ }^{30}$ Simon Kuznets, "Economic Growth and Income Inequality", The American Economic Review, vol. 45, núm. 1, March 1955, pp. 1-28. 
Sin embargo, posteriormente Deninger y Squire ${ }^{31}$ concluyen que, cuando prueban esta hipótesis país por país, no tiene soporte empírico en $90 \%$ de los países investigados. Analizando los datos para México, no se pueden obtener conclusiones claras. Entre 1950 y 2010 , hay períodos en los que aumenta el crecimiento y se reduce la desigualdad (1963-1984) y otros en los que hay mayor crecimiento y empeora la desigualdad (1984-1994, 1996-2000). De igual forma, en los períodos en que hubo un decrecimiento importante, como en 1994-1996 y 2008-2010, la desigualdad mejoró. La evidencia empírica no es clara entre ambas variables, y las implicaciones teóricas tampoco lo son.

\section{GRÁFICA 7}

\section{Desigualdad en México, 1950-2010}

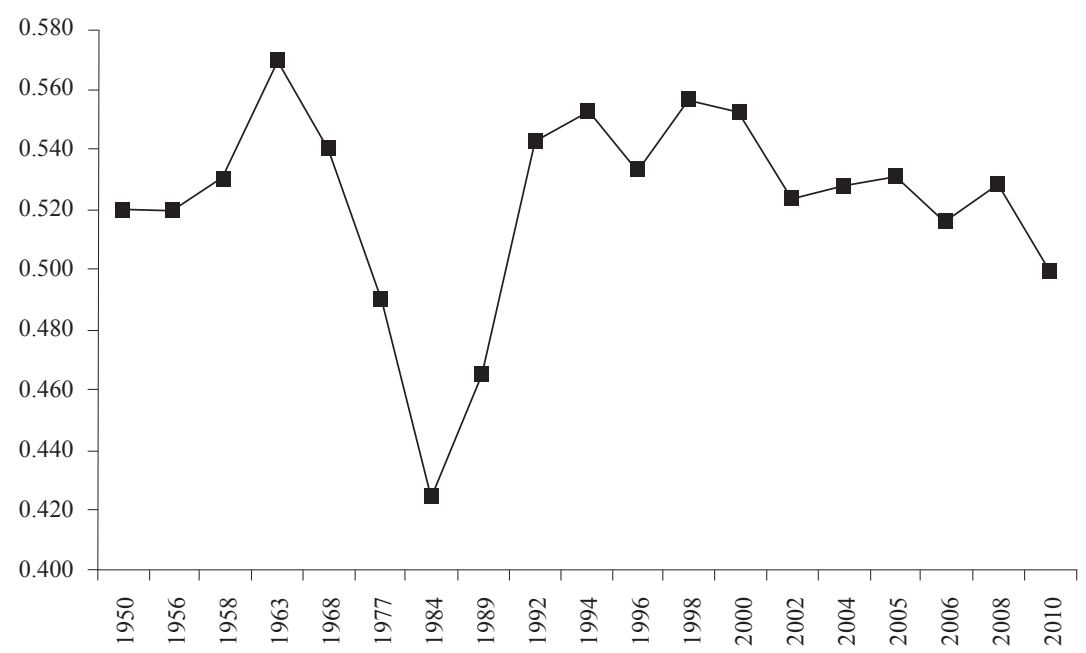

Nota: Debido al cambio en los factores de expansión cambia la serie a partir de 1992.

Fuentes: De 1950 a 1982 datos de Székely (2003). A partir de 1992 estimaciones del CONEVAL con base en las ENIGH 1992-2010 (coeficiente de GINI del ingreso neto total per capita a nivel de hogar).

En resumen, regresemos a nuestra comparación de México con Ucrania. En promedio, México tiene un nivel de vida (PIB per capita) mayor. Pero la desigualad en México es más grande. Mientras que el índice de Gini en nuestro país en 2008 era de 0.52, en Ucrania era de

${ }^{31}$ Klaus Deininger y Lyn Squire, Measuring Income Inequality: A New Data-Base, 1998, Cambridge MA, Working Papers from Harvard Institute for International Development. 
$0.27 .^{32}$ Lo anterior implica que el $10 \%$ más pobre recibía el $1.8 \%$ del ingreso total en México, pero el 4.1\% en Ucrania. El 4.1\% de 4,524 dólares es más grande que el 1.8\% de 7,749 dólares, y por ello, el ingreso (el nivel de vida) de los más pobres en Ucrania es mayor que el de los más pobres en México. El nivel de vida promedio en México es mayor, pero el nivel de vida de los más pobres es más alto en Ucrania ¿En qué país hay mayor bienestar o desarrollo económico o justicia? Según John Rawls, sin duda, en un país como Ucrania.

\section{Pobreza}

El único posible resultado que podríamos tener después de analizar las variables de desarrollo económico anteriores es que la pobreza en México debe ser muy grande. Tenemos en primer lugar un pastel de tamaño insuficiente debido al poco crecimiento de las últimas décadas. Además, el reducido pastel está mal distribuido, lo cual implica necesariamente que hay un grupo alto de personas que reciben ingresos por debajo de lo mínimo necesario para una subsistencia decorosa y justa: un alto porcentaje de la población en México vive en pobreza.

La definición y medición de la pobreza es controversial pues si bien el concepto de pobreza es más o menos claro, la forma de medirla operativamente no lo es. En la práctica ha habido muchas formas de medir pobreza y cada una de las metodologías tiene sus ventajas y desventajas. Actualmente, la medición oficial de la pobreza en el país es realizada por el Consejo Nacional de Evaluación de la Política de Desarrollo Social (CONEVAL), que es un organismo público descentralizado de la Administración Pública Federal con autonomía técnica, garantizada por los por seis Investigadores Académicos que forman parte de la entidad y fueron elegidos democráticamente por medio de Convocatoria Pública.

La definición de pobreza considera las condiciones de vida de la población a partir del bienestar económico y de los derechos sociales, como lo señala la Ley General de Desarrollo Social (2004). México es el primer país del mundo en tener una medición de pobreza que utiliza varias dimensiones: medición de pobreza multidimensional. La venta-

\footnotetext{
${ }^{32}$ The World Bank, World Development Indicators 2012, Washington, World Bank.
} 
ja de esta metodología, es que efectivamente la pobreza que padecen las personas no sólo se refleja en el ingreso, sino también en la falta de acceso a los derechos sociales. Por esta razón, esta forma de medir pobreza sigue incluyendo el ingreso, pero ahora también incorpora otros factores.

La dimensión del bienestar económico incluye las necesidades asociadas a los bienes y servicios que puede adquirir la población mediante el ingreso. ${ }^{33}$ La dimensión de los derechos sociales se integra con base en las carencias de la población en el ejercicio de sus derechos para el desarrollo social; este espacio incluye los siguientes indicadores de carencias asociados a derechos: acceso a los servicios de salud, acceso a la seguridad social, acceso a los servicios básicos en la vivienda, calidad y espacios de la vivienda, rezago educativo y acceso a la alimentación.

Una persona se encuentra en situación de pobreza cuando no tiene garantizado el ejercicio de, al menos, uno de sus derechos para el desarrollo social, y si sus ingresos son insuficientes para adquirir los bienes y servicios que requiere para satisfacer sus necesidades. ${ }^{34}$

En el Cuadro 7 se muestra la incidencia, el número de personas y las carencias promedio en los indicadores de pobreza en México en el período 2008-2010. En 2010, la población en situación de pobreza era de $46.2 \%$, es decir, 52 millones de personas. Podemos observar que respecto de 2008, la pobreza aumentó en 3.2 millones de personas. El aumento de la población en situación de pobreza se debió a que se incrementó el número de personas con ingresos bajos y con carencia en el acceso a la alimentación, como resultado de la crisis económica internacional que inició en 2008 y del aumento en los precios de los alimentos.

${ }^{33}$ La línea de bienestar identifica a la población que no cuenta con los recursos suficientes para adquirir los bienes y servicios que requiere para satisfacer sus necesidades (alimentarias y no alimentarias). La línea de bienestar mínimo identifica a la población que, aun al hacer uso de todo su ingreso en la compra de alimentos, no puede adquirir lo indispensable para tener una nutrición adecuada. En 2010 la línea de bienestar se calculó para el ámbito urbano en $\$ 2,114$ por persona y en $\$ 1,329$ para el rural. Asimismo, la línea de bienestar mínimo se calculó para este mismo año en $\$ 978$ por persona para las zonas urbanas y en $\$ 684$ por persona para las rurales.

${ }^{34}$ CONEVAL, Metodología para la medición multidimensional de la pobreza en México, 2009, México, D. F. 
Destaca que el número de carencias promedio se redujo de 2.7 a 2.5, ya que durante este período aumentó la cobertura básica de la educación, el acceso a los servicios de salud, la calidad y espacios de la vivienda, los servicios básicos en las viviendas, y la seguridad social.

\author{
Cuadro 7 \\ Incidencia, número de personas y carencias promedio \\ en los indicadores de pobreza, 2008-2010
}

\begin{tabular}{|c|c|c|c|c|c|c|}
\hline \multirow[b]{3}{*}{ Indicadores } & \multicolumn{6}{|c|}{ Estados Unidos Mexicanos } \\
\hline & \multicolumn{2}{|c|}{ Porcentaje } & \multicolumn{2}{|c|}{$\begin{array}{c}\text { Millones de } \\
\text { personas }\end{array}$} & \multicolumn{2}{|c|}{$\begin{array}{l}\text { Carencias } \\
\text { pormedio }\end{array}$} \\
\hline & 2008 & 2010 & 2008 & 2010 & 2008 & 2010 \\
\hline \multicolumn{7}{|l|}{ Pobreza } \\
\hline Población en situación de pobreza ${ }^{1}$ & 44.5 & 46.2 & 48.8 & 52.0 & 2.7 & 2.5 \\
\hline Población en situación de pobreza moderada ${ }^{3}$ & 33.9 & 35.8 & 37.2 & 40.3 & 2.3 & 2.1 \\
\hline Población en situación de pobreza extrema ${ }^{3}$ & 10.6 & 10.4 & 11.7 & 11.7 & 3.9 & 3.7 \\
\hline Población vulnerable por carencias sociales ${ }^{4}$ & 33.0 & 28.7 & 36.2 & 32.3 & 2.0 & 1.9 \\
\hline Población vulnerable por ingresos ${ }^{5}$ & 4.5 & 5.8 & 4.9 & 6.5 & 0.0 & 0.0 \\
\hline Población pobre y no vulnerable & 18.0 & 19.3 & 19.7 & 21.8 & 0.0 & 0.0 \\
\hline \multicolumn{7}{|l|}{ Privación social } \\
\hline Población con al menos una carencia social & 77.5 & 74.9 & 85.0 & 84.3 & 2.4 & 2.3 \\
\hline Población con al menos tres carencias sociales & 31.1 & 26.6 & 34.1 & 29.9 & 3.7 & 3.6 \\
\hline \multicolumn{7}{|l|}{ Indicadores de carencia social } \\
\hline Rezago educativo & 21.9 & 20.6 & 24.1 & 23.2 & 3.2 & 3.0 \\
\hline Carencia por acceso a los servicios de salud & 40.8 & 31.8 & 44.8 & 35.8 & 2.9 & 2.8 \\
\hline Carencia por acceso a la seguridad social & 65.0 & 60.7 & 71.3 & 68.3 & 2.6 & 2.5 \\
\hline Carencia por calidad y espacios de la vivienda & 17.7 & 15.2 & 19.4 & 17.1 & 3.6 & 3.5 \\
\hline Carencia por acceso a los servicios básicos en la vivienda & 19.2 & 16.5 & 21.1 & 18.5 & 3.5 & 3.3 \\
\hline Carencia por acceso a la alimentación & 21.7 & 24.9 & 23.8 & 28.0 & 3.3 & 3.0 \\
\hline \multicolumn{7}{|l|}{ Bienestar } \\
\hline Población con un igreso inferior a la línea de bienestar mínimo & 16.7 & 19.4 & 18.4 & 21.8 & 3.0 & 2.7 \\
\hline Población con un ingreso inferior a la línea de bienestar & 49.0 & 52.0 & 53.7 & 58.5 & 2.5 & 2.2 \\
\hline
\end{tabular}

${ }^{1}$ Población un ingreso inferior al valor de la línea de bienestar (LB) y que padece al menos una carencia social.

${ }^{2}$ Población que presenta al menos 3 de las 6 carencias sociales, y cuenta con un ingreso inferior al valor de la línea de bienestar mínimo (LBM).

${ }^{3}$ Población pobre que no está en pobreza extrema.

${ }^{4}$ Población que presenta una o más carencias sociales pero cuyo ingreso es superior al valor de la LB.

${ }^{5}$ Población que no presenta carencias sociales y cuyo ingreso es inferior o igual a la LB.

Nota: Para los años anteriores a 2008, no se cuenta con información de todos los factores que marca la Ley General de Desarrollo Social para la medición de la pobreza.

Fuente: estimaciones del CONEVAL con base en el MCS-ENIGH 2008 y 2010, y CONEVAL, op. cit.

Pero esta medición, si bien proviene de la Ley y de un trabajo metodológico riguroso por parte del CONEVAL, no es la única que existe. El indicador tradicional para medir la pobreza es el porcentaje de los 
individuos con ingresos menores al valor de un umbral respecto del total de la población. A esto se le conoce como pobreza por ingresos. Si bien no es la forma oficial de medir pobreza hoy en día, históricamente se tienen cifras para México usando tres umbrales distintos: el valor de una canasta alimentaria, ${ }^{35}$ el valor mínimo para cubrir necesidades de alimentación, salud y educación, y el valor mínimo para cubrir necesidades de alimentación, salud, educación, vestido, calzado, vivienda y transporte público. Estos se conocen como pobreza alimentaria, pobreza de capacidades y pobreza patrimonial, respectivamente. Con esta metodología se puede obtener, no sin dificultades, la evolución de la pobreza en México desde 1950 hasta 2010, como se muestra en la Gráfica $8 .{ }^{36}$

GRÁFICA 8

Pobreza por ingresos en México, 1950-2010

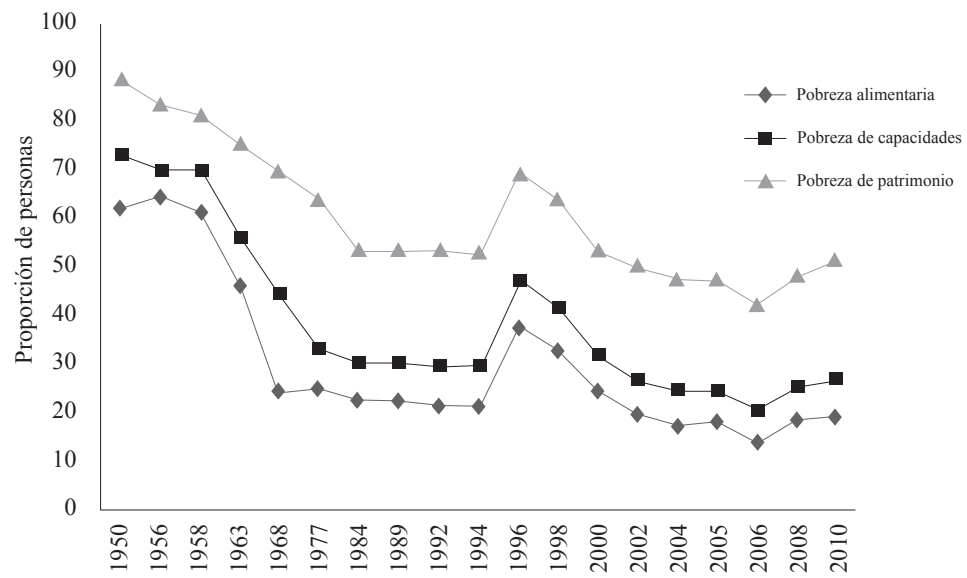

Fuentes: Hasta 1989 Székely (2003) y a partir de 1992 estimaciones del CONEVAL con base en las ENIGH 1992-2010.

De la gráfica se destaca en primer lugar que, de acuerdo con esta información, la pobreza se redujo de manera importante entre 1950 y principios de los ochentas. En segundo lugar, el nivel de pobreza ha permanecido casi inalterado desde 1984, con alzas y bajas entre 1994

${ }^{35}$ Se hace uso de la canasta elaborada por ENIGH-CEPAL en 1992. Para ver la evolución de la canasta alimentaria, ver Anexo 1.

${ }^{36} \mathrm{~A}$ lo largo de estos años, las fuentes de información no han sido homogéneas, pero sí suficientes para poder obtener un panorama tentativo de la evolución de la pobreza en el largo plazo. 
y 2010. Finalmente, podemos observar que a pesar de la reducción que se observa desde 1950 y posteriormente desde 1996 hasta 2006, la pobreza continúa en niveles muy elevados. En 2010 el 51.3\% de la población aún estaba en pobreza de patrimonio.

Como el tamaño de la economía afecta el nivel de pobreza, la Gráfica 9 compara el porcentaje de pobreza en México con países que tienen similar PIB per capita. Se puede notar que en esta selección, a excepción de Colombia y Brasil, la pobreza más alta se registra en México. Como es de esperarse, la distribución del ingreso juega aquí un papel importante.

GRÁFICA 9

Porcentaje de personas por debajo de la línea de pobreza de 2 dólares diarios, 2008

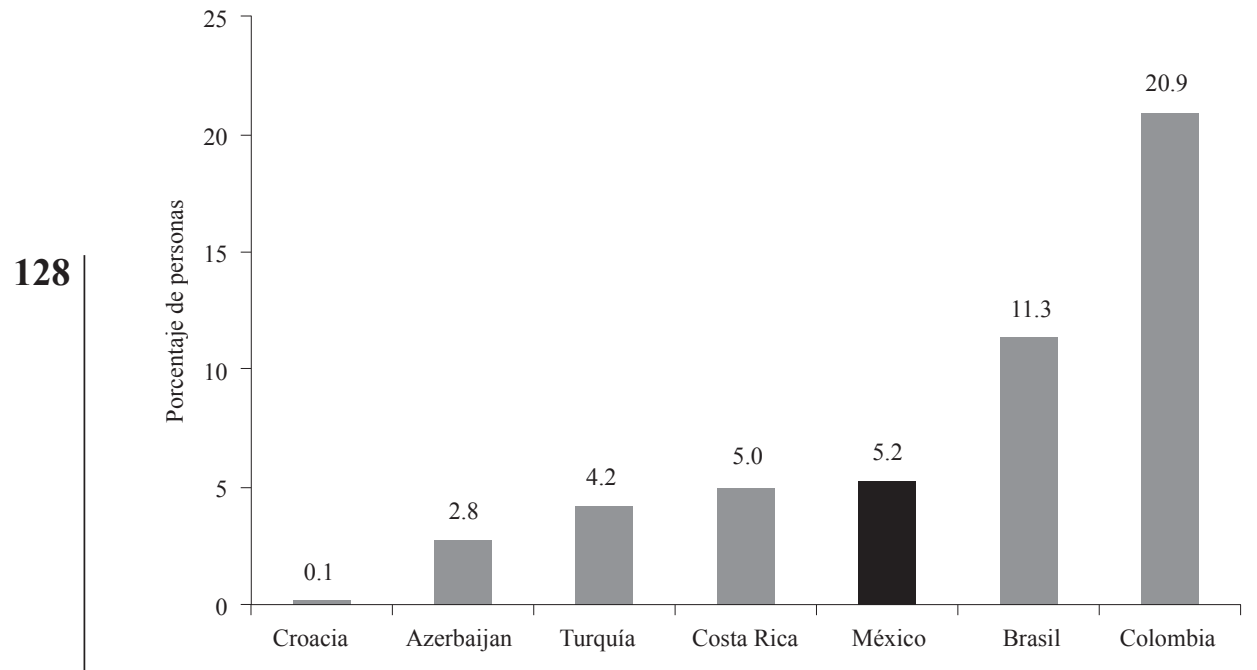

Fuente: World Development Indicators 2012, Banco Mundial.

Pobreza, crecimiento económico y desigualdad

En la Gráfica 8 se destaca que la pobreza disminuyó de manera importante entre 1950 y 1984 . El crecimiento per capita promedio de este 
período fue de $3 \%$, lo cual es relativamente alto, tomando en cuenta los decrecimientos en 1982 y 1983 . Esto quiere decir que es muy probable que el crecimiento haya contribuido a disminuir la pobreza. La pobreza ha tenido un comportamiento contra-cíclico respecto del crecimiento económico. Períodos de crecimiento económico relativamente alto coinciden con que la pobreza se reduce, especialmente la pobreza moderada. Autores como Dollar y Kraay, Foster y Székely, Kakwani, Bourguignon, y Hadaad y Kanbur ${ }^{37}$ han analizado extensamente la relación entre crecimiento y pobreza. Si bien no hay un consenso sobre en cuánto cae la pobreza ante incrementos del crecimiento, los autores concuerdan en que el crecimiento económico favorece la reducción de la pobreza. Posiblemente el mejor ejemplo de cómo la situación económica, y en especial el crecimiento afecta a la pobreza es analizar el período 1994-1996. El descalabro económico de finales de 1994 tuvo como consecuencia una reducción en el PIB per capita de 8.6\% entre 1995 y 1994. Entre 1994 y 1996 casi 16 millones de personas ingresaron a la pobreza alimentaria a raíz de una reducción de casi $30 \%$ en el ingreso real promedio de la población. Por otro lado, el aumento registrado entre 2008 y 2010 de las personas en pobreza alimentaria, derivado de la crisis y del aumento en el precio de los alimentos, fue más moderado. Es posible que esto se deba a los apoyos otorgados por los programas sociales a la población más vulnerable, a pesar de que en promedio el PIB per capita cayó $1.6 \%$ anual.

Por el contrario, se observa que la pobreza se ha reducido de manera importante entre 1996 y 2006. Durante este período, la tasa de crecimiento promedio anual del PIB per capita fue de $2.3 \%,{ }^{38}$ que si bien fue un crecimiento modesto, se acompañó de una importante reducción en la inflación, un aumento en el empleo, un incremento de

${ }^{37}$ Cfr. David Dollar y Aart Kraay, "Growth is Good for the Poor", Journal of Economic Growth, vol. 7, núm. 3, September 2002, pp. 195-225; James Foster y Miguel Székely, "Is Economic Growth Good for the Poor? Tracking Low Incomes Using General Means", documento presentado en el Asia and Pacific Forum on Poverty: Reforming Policies and Institution for Poverty Reduction, 2000, Asian Development Bank; Kawani, op. cit.; François Bourguignon, "The poverty-growth-inequality triangle", ponencia presentada en el Indian Council for Research on International Economic Relations, 2004, Nueva Delhi; y Lawrence Haddad y Ravi Kanbur, Is There an Intra-Household Kuznets Curve?, 1990, Washington, The World Bank, Office of the Vice President, Development Economics.

${ }^{38} \mathrm{El}$ promedio fue de $4.0 \%$ entre 1996 y 2000. 
los salarios reales y una expansión de los programas sociales. La inflación mensual pasó de aproximadamente $3.59 \%$ a $0.52 \%{ }^{39}$ en este período; el empleo total creció $46.7 \%{ }^{40}$ y los salarios reales crecieron $25.8 \%{ }^{41}$ Finalmente, durante este período se creó y expandió el programa social Progresa-Oportunidades, el cual otorga apoyos monetarios y en especie a familias que viven en condiciones de pobreza; en 2006 el programa benefició a cinco millones de familias (en 2010 el número de hogares beneficiarios del programa ascendió a 5.8 millones de hogares). Esto sugiere que es necesario complementar el crecimiento económico con medidas más concretas enfocadas a la población en pobreza extrema, así como con una importante estabilidad macroeconómica. El control de la inflación y el diseño de programas directos de alivio a la pobreza son indispensables para acelerar el combate a la pobreza extrema en un país como México.

Otro factor que incide sobre la pobreza, como se ha dicho en más de una ocasión, es la desigualdad del país. Con la información que tenemos no podemos saber cuánto contribuyó el crecimiento o la distribución del ingreso a la pobreza, pero el Banco Mundial ${ }^{42}$ hizo un ejercicio de simulación en el cual se pueden analizar los efectos de ambas variables sobre la pobreza extrema. El Cuadro 8 señala al menos dos cosas. Si mantuviéramos sin cambio la desigualdad, un crecimiento mayor implicaría tener en el 2015 un nivel de pobreza extrema menor. De esta forma, si el país tuviera el mismo coeficiente de Gini que en 2002, la pobreza caería al 5.5\% con un crecimiento promedio del 5\% y se reduciría sólo al 15.3 con un crecimiento del 2\%. Asimismo, el cuadro permite ver que si la distribución mejorara, el impacto sobre la pobreza sería mayor. Con un crecimiento de $2 \%$, la pobreza fluctuaría en el 2015 entre el 18.3\% y el 8.3\%, dependiendo de si la desigualdad empeorara o mejorara en este lapso.

${ }^{39}$ Inflación mensual de diciembre de 1995 y de diciembre de 2006 respectivamente, INEGI.

${ }^{40} \mathrm{Se}$ refiere exclusivamente al total de los trabajadores permanentes y eventuales en activo asegurados en el IMSS, es decir, no incluye a los asegurados de otras modalidades como seguro facultativo, para estudiantes y no estudiantes, seguro de salud para la familia y los de continuación voluntaria. Instituto Mexicano del Seguro Social, 2012.

${ }^{41}$ Salario de cotización al IMSS, ibid.

${ }^{42}$ The World Bank, La pobreza en México: una evaluación de las condiciones, las tendencias y la estrategia de gobierno, 2004, México, Banco Mundial. 
CUADRO 8

Escenarios alternativos para la pobreza alimentaria basada en activos en 2015

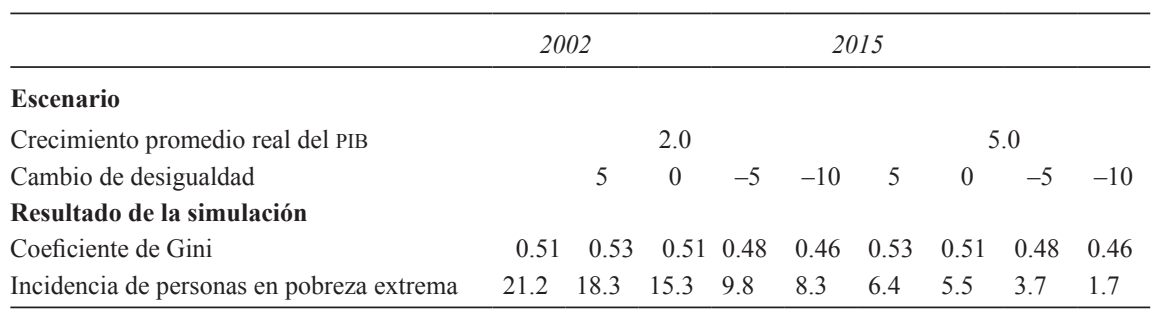

Fuente: Banco Mundial, op. cit.

Por tanto, dos factores en los que México no ha tenido buenas cuentas en las últimas décadas, la desigualdad y el crecimiento, sin duda hacen que la pobreza, uno de los problemas sociales y económicos más graves e injustos, sea muy alta. Los retos para el país, en materia de desarrollo económico, son enormes.

\section{Retos}

La historia reciente del desarrollo económico en México no es alentadora. Tenemos un nivel de vida mediocre, producto de un pobre crecimiento económico durante las últimas décadas. La desigualdad de oportunidades, que se traduce en desigualdad del ingreso, es un problema histórico que no cede y que coloca a México como uno de los países más desiguales del mundo. Todo esto se refleja en el nivel de pobreza: un poco más de la mitad de la población es pobre en el país.

Si los problemas del país tienen ya años y muchas veces décadas, es claro que la solución no puede ser inmediata ni mágica. Si hoy lleváramos a cabo políticas adecuadas, éstas sólo rendirán frutos en el mediano y largo plazo. Si en cambio hoy no hacemos nada por cambiar los problemas más importantes, el país puede hundirse fácilmente en una situación peor a la actual en pocos años. En un mundo globalizado y en competencia, no avanzar implica necesariamente retroceder. Por ello, en este espacio haremos una breve reflexión sobre los retos más importantes del país y (algunas) posibles soluciones. 


\section{Preparando el impostergable crecimiento}

Es necesario avanzar en muchos frentes para abonar el crecimiento económico. El motor directo del crecimiento es la inversión, tanto nacional - pública y privada-como internacional. La inversión expande la capacidad productiva de los países incrementando su frontera de posibilidades de producción. La inversión implica ahorrar hoy para obtener ganancias mayores en el futuro. Pero la inversión no se da por decreto. El inversionista - sea éste de pequeña o gran escala- busca obtener beneficios concretos de su inversión y no estará dispuesto a arriesgar el capital si no existen las condiciones necesarias para afrontar el riesgo natural que implica invertir. Señalamos aquí algunas áreas que apoyarían una mejor inversión en el país.

\section{Educación}

En las próximas décadas estaremos ofreciendo la mayor cantidad de trabajadores potenciales para el mercado laboral, debido a la estructura demográfica del país. Éste puede ser o un bono demográfico que incrementará la producción del país si esa mano de obra está preparada, o un enorme pagaré si esos trabajadores son más bien una carga improductiva. La educación es, por tanto, la llave maestra del crecimiento de largo plazo. Se requiere entonces:

- Una mayor inversión en educación pública, especialmente en niveles de educación básica - preescolar, primaria, secundaria y media superior-, para incrementar cobertura y, sobre todo, para mejorar la calidad en los tres ciclos.

- Llevar a cabo cambios institucionales, especialmente al interior del sindicato de maestros, el más grande y poderoso de México, para que los incrementos presupuestales en educación no sólo sean para mejorar los salarios de maestros y líderes improductivos, sino que realmente se mejore la calidad de la educación. De nada servirá tener al 100\% de la población con educación básica, si ésta no es de calidad y no puede competir con la mano de obra de otros países. 
- El gobierno deberá seguir impulsando la educación universitaria, pero teniendo esquemas de financiamiento adecuados, novedosos y más justos. Hoy en día el gasto en educación universitaria es regresivo, es decir, se otorgan más recursos a los deciles de ingreso más altos, producto de la falta de oportunidades que suceden a partir de la preparatoria y del creciente costo de oportunidad. La propuesta es que la educación universitaria sea financiada parcialmente por las familias, pero que se otorguen becas completas, que cubran el costo de oportunidad, para los estudiantes capaces y con menores niveles de ingreso.

- Fomentar y tomar más en cuenta la educación técnica. Otros países han basado su progreso en la educación técnica que apoya directamente el proceso productivo. En México, la educación técnica no es bien vista, en parte porque el curriculum de las escuelas técnicas ha estado muy alejado del proceso productivo.

- Fomentar cambios en el federalismo educativo, para que los estados efectivamente tengan un control adecuado de los recursos educativos y los canalicen a las áreas que puedan mejorar la cobertura y calidad, pero que haya una buena rendición de cuentas de los gobiernos locales.

- Seguir promoviendo la evaluación educativa, dando a conocer los resultados a nivel escuela y a nivel maestro.

\section{Infraestructura}

La ventaja que brinda estar cerca del mercado más grande del mundo, económicamente hablando, se viene abajo cuando la infraestructura de transportes y comunicaciones tiene un alcance limitado. La conexión a través de carreteras con las zonas de mayor pobreza en los estados del sur-sureste transformará económicamente esas entidades y revertirá en unos años una desigualdad norte-sur que cada vez se acentúa más.

- Es importante mejorar la regulación de telecomunicaciones para fomentar verdaderamente la competencia en este sector. Hoy sigue habiendo un líder claro en este mercado y las prácticas monopólicas no son cosa del pasado. Enfrentar estos monopolios significa tener mejor servicio y menores costos, lo cual beneficia no sólo al consumidor promedio, sino que incrementará la calidad y la oferta para incentivar el crecimiento. 


\section{Competencia Económica}

El hecho de que las oportunidades no sean precisamente iguales en el país implica que México es un país de monopolios. Sólo unos pocos pueden tener acceso al financiamiento, sólo unos cuantos pueden ser dueños de las telecomunicaciones, sólo el gobierno puede invertir en energía, petróleo y gas, sólo algunos pueden ir escuelas privadas, sólo unos cuantos pueden tener puestos en el gobierno, sólo algunos pueden tener concesiones en ciertos mercados $\mathrm{y}$, hasta hace poco, sólo un partido político podía acceder a la presidencia de la República. Se propone:

- Continuar fortaleciendo a la Comisión Federal de Competencia para que tenga el poder suficiente de enfrentar y disolver monopolios en los mercados que así lo exijan.

- Es fundamental que se abra la posibilidad de que la inversión privada, con una buena regulación del Estado, pueda financiar parte de estos servicios. Con ello se mejorará el servicio, bajarán los precios y se garantizará el abasto energético del futuro.

\section{Reformas estructurales}

Por casi setenta años el país estuvo prácticamente cerrado a la competencia internacional, había un solo partido político dominante y por ello el tipo de instituciones necesario para el desarrollo tenía que reflejar este entorno. Hoy México vive otra realidad -mayor apertura, más democracia- que implica necesariamente cambiar las reglas del juego en varios aspectos. Esto no es sencillo, naturalmente. Para mejorar la competitividad del país, que se traduce en más inversión y empleos, es importante acelerar las siguientes reformas o cambios regulatorios:

- Reforma Hacendaria. Que le brinde al Estado la generación de recursos suficientes para poder afrontar los cambios que el país requiere en todos los campos que se han señalado.

- Reforma Educativa. Como ya se había dicho, para mejorar la calidad y hacer efectivo el federalismo con rendición de cuentas. 
- Reforma al sistema de impartición de justicia. A inicios del siglo XXI, el Estado de derecho en México empieza a parecer una ilusión más o menos lejana. La enorme impunidad que impera en muchas actividades sociales afecta a la inversión productiva y premia la ilegalidad. Son necesarios cambios substanciales en la forma de operar de todas las instituciones involucradas en este proceso.

- Reforma del Estado. Como se verá posteriormente, esta reforma implica modificar las actuales reglas del juego político, que ya no son eficaces para lograr acuerdos en un país que ha cambiado en los ámbitos económico y social.

\section{Ampliando las oportunidades}

Algunas de las acciones anteriores implican brindar y ampliar las oportunidades de diversos grupos que ahora están en desventaja. Pero ante la magnitud de la desigualdad en México, quizás vale la pena mejorar otros ámbitos:

\section{Discriminación}

De acuerdo con la Encuesta Nacional sobre Discriminación en México (ENADIS) 2010, México es un país con discriminación. Si S. Engerman y K. Sokoloff están en lo correcto, ${ }^{43}$ en el sentido de que buena parte de la desigualdad se debe a estructuras históricas que vienen desde tiempos de la Colonia, entonces hoy en día, algunas reglas del juego, formales o informales, implicarán algún grado de discriminación.

- Por ello será necesario reforzar las actividades para luchar frontalmente contra la discriminación de todo tipo. Habrá que brindar más recursos a la Comisión Nacional Contra la Discriminación (CONAPRED), para que sus actividades generen mayor conciencia, así como cambios institucionales que eliminen prácticas discriminatorias.

${ }^{43}$ Engerman y Sokoloff, op. cit. 


\section{Combatiendo la pobreza}

La pobreza sin duda se reduciría si pudiéramos lograr resolver los problemas de crecimiento y distribución de las oportunidades. Pero ante la magnitud de la pobreza en México, es necesario llevar a cabo políticas adicionales.

Dada la nueva situación del país, en el que la competencia y la productividad son herramientas importantes para mejorar la situación personal y del país, los programas sociales necesarios para acelerar el combate contra la pobreza ya no pueden ser de las características que se tenían anteriormente (e incluso muchos de hoy día). Los programas de corte asistencial, sin participación por parte de los grupos involucrados y que no incrementen las capacidades de las familias deberán quedar en el pasado.

- La reducción de la pobreza, e indirectamente de la desigualdad, se podrá acelerar si se desarrollan programas sociales focalizados, que mejoren las capacidades de la población y que fomenten o promuevan la participación social de las familias y las comunidades. El programa Oportunidades, que se inició con el nombre de Progresa en 1997, cumple con algunas de estas características, a excepción de la participación comunitaria. Este programa ha sido evaluado rigurosamente y presenta muy buenos resultados en cuanto a que ha contribuido a aumentar la matrícula escolar, y ha mejorado los niveles de salud y nutrición de los niños que participan en el programa. Todavía está pendiente el verdadero impacto de largo plazo sobre la población beneficiaria.

- Crecimiento económico. La pobreza no se reducirá con más y mejores programas sociales, aunque fueran incluso más eficientes que el programa Oportunidades. Nos seguiremos engañando si pensamos que el combate a la pobreza sólo se tiene que dar mediante de programas. Si México no crece, si no se generan empleos, si el salario real no se incrementa, la pobreza simple y sencillamente no puede reducirse de manera sistemática.

Repensar México

Debido a que los problemas que aún tenemos como país son muchos, podríamos seguir incluyendo sugerencias específicas para mejorar 
aspectos concretos con el temor de que este ensayo se alargue mucho. En este final del camino quisiera plantear rápidamente un problema estructural de la economía mexicana, el cual afecta a la pobreza, la creación de empleos y la seguridad social, es decir, afecta los derechos sociales de los individuos, lo cual hace pensar que una posible solución son los cambios coordinados en pocas áreas, en vez de una multiplicidad de cambios descoordinados en muchas áreas. La idea principal es de Santiago Levy. ${ }^{44}$

A inicios del siglo pasado la creación del Instituto Mexicano del Seguro Social (IMSS) se hizo implícitamente bajo lo siguientes supuestos: la economía crecería de manera acelerada, se crearían puestos de trabajo suficientes y por tanto tendríamos a prácticamente todos los trabajadores afiliados al IMSS; es decir, se tendría una acceso universal de la seguridad social. Los obreros lo tendrían vía el IMSS y los patrones vía sus propias contribuciones personales.

Muy pronto se vio no sólo que el IMSS no afilió a un gran número de trabajadores, sino que además el modo de financiar al IMSS encarecía la creación de empleos: para financiar al IMSS, la empresa, el trabajador (y el gobierno) aportan recursos que pueden incrementar el costo laboral en casi 35\%. La creación de pocos empleos formales (que tienen seguridad social), que es el ingrediente más importante para abatir la pobreza, es muy débil, implica que más de la mitad de la población no tiene seguridad social.

La forma de solucionar el problema de seguridad social no es hoy el adecuado ante una bajísima creación de empleo, una baja cobertura de seguridad social y una pobreza que se reduce lentamente. ¿Por qué no re-pensar la forma de atacar estos problemas de manera simultánea y así mejorar los derechos sociales de la población?

- Transitar hacia un esquema que brinde seguridad social universal, con lo cual se desliga el acceso a este derecho de la situación laboral del individuo o la familia. El paquete básico de seguridad social puede incluir salud, pensión de vejez, seguro de vida y de enfermedad.

${ }^{44} \mathrm{~S}$. Levy, Buenas intenciones, malos resultados. Política Social, Informalidad y Crecimiento Económico en México, 2010, México, Océano. 
- Reducir paulatinamente el costo laboral que implica el pago de IMSS e INFONAVIT al desvincular la seguridad social del empleo. Con esto se tendría una gran inversión y creación de empleos. Lo anterior genera más empleo, mayor productividad y salarios en el mediano plazo, que son los ingredientes más importantes para reducir la pobreza.

- Financiar la seguridad social vía impuestos generales, lo cual ampliaría la base de pago de impuestos y de esta forma el ciudadano tiene derechos sociales: seguridad social, salud, trabajo digno, pero también cumple con sus obligaciones mínimas: pago de impuestos. ${ }^{45}$

\section{Los caminos de la política}

Mejorar la calidad de la educación, aprobar las reformas estructurales, endurecer el combate a los monopolios, llevar a cabo programas sociales focalizados, cambiar el sistema de seguridad social y tributario, son todas ellas acciones que para que se implementen debe haber un acuerdo -no siempre fácil- con diversos grupos. Posiblemente las fórmulas técnicas para mejorar el crecimiento - educación, infraestructura, tecnologíason ya conocidas por muchos actores. Pero faltan, ni más ni menos, el convencimiento y la puesta en marcha, y esto es una tarea eminentemente política.

Por ello, es necesario reforzary mejorar la actividad política al interior y entre los poderes de la Unión, así como llevar a cabo una reforma del Estado que construya los nuevos canales de comunicación en el nuevo escenario democrático del país y permita lograr acuerdos entre todas las partes. Transformar el desarrollo económico de México es una tarea eminentemente política, con algunos elementos técnicos, y no al revés.

\section{No todo está perdido}

D. Dresser escribió: "Hoy el pesimismo recorre al país e infecta a quienes entran en contacto con él. México vive obsesionado con el fracaso. Con la victimización. Con todo lo que pudo ser pero no fue. ${ }^{45}$ Ibidem. 
Con lo perdido, lo olvidado, lo maltratado". ${ }^{46}$ No dudo que podría ser el caso. Es posible que se refleje también cierto pesimismo en el tono de este artículo. Los datos duros y saber que en México podemos hacer muchos más de lo que hemos logrado me lleva a estas conclusiones.

Pero es cierto asimismo que México es un país que tiene un gran potencial. Su dotación de activos y riquezas lo colocan entre los mejores del mundo.Su historia y su cultura lo hacen un país profundo y complejo, las agradables vivencias cotidianas de cada uno lo convierten en casa y refugio. Dresser ha sido justificadamente optimista: "Frente a las razones para perder la fe están todas las razones para recuperarla. Los murales de Diego Rivera. Las enchiladas suizas de Sanborn's. Las mariposas en Michoacán... Los tacos al pastor con salsa y cilantro. El humor de Carlos Monsiváis. El mar en Punta Mita. Las canciones de Julieta Venegas. La poesía de Efraín Huerta. El Espacio Escultórico al amanecer. Cualquier Zócalo cualquier domingo". ${ }^{47}$ Tiene mucha razón. En mi lista del país que cotidianamente admiro, incluiría a Coyoacán y su mercado, al bosque de Tlalpan en las mañanas, al sorprendente ingenio de Andrés Bustamante y Trino; el Café de la Parroquia en Veracruz, los portales de Córdoba, el lechón a la leña de Tuxtepec, Gandhi y sus libros, y la cocina de Patricia Quintana y Mónica Patiño.

El gran problema es que todo esto no es suficiente para tener un adecuado desarrollo económico. Las grandes civilizaciones del pasado -Egipto, Siria, Turquía, Irak- con su historia, su poder bélico, su ciencia y su gastronomía, no garantizaron el buen desempeño económico y social: hoy en día son una pálida sombra frente a otros países con menos folklore.

México necesita transformar sus instituciones y ajustarlas a la nueva realidad; si lo logramos, podremos transformar los activos, riquezas, historia y costumbres del país en beneficios concretos para la mayoría de sus habitantes. La vida cotidiana sería de mayor riqueza para todos. Si no actuamos pronto, el futuro de las próximas generaciones se verá

${ }^{46}$ Denise Dresser, "El País de Uno”, Reforma, 24 de enero de 2005.

${ }^{47}$ Ibidem. 
aún más comprometido que el nuestro y nos quedarán sólo recuerdos del país que pudo ser, un poco de orgullo y de nacionalismo que en nada ayudarán a mejorar el nivel de vida de nuestros hijos.

\section{Anexo 1}

CUADRo 1

Líneas de pobreza por ingresos, 1992-2010

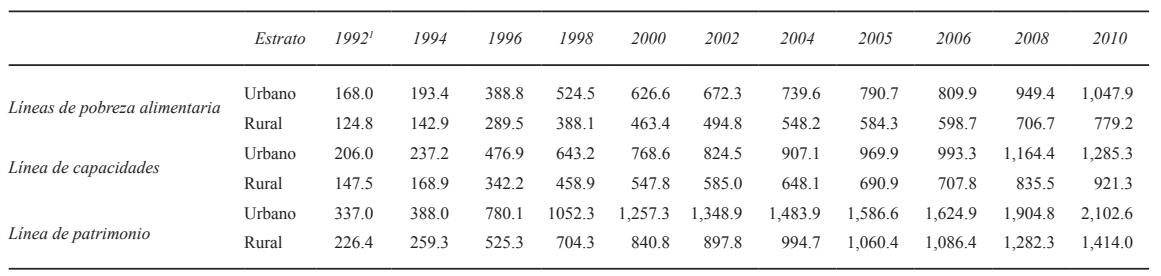

${ }^{1}$ Para los años previos a 1993 se realiza el ajuste por el cambio a nuevos pesos.

Fuente: Estimaciones del CONEVAL con información del Banco de México e INEGI. 